\title{
XXX. A quantitative study of the high-frequency induction-coil
}

\section{W. P. Boynton}

To cite this article: W. P. Boynton (1898) XXX. A quantitative study of the highfrequency induction-coil , Philosophical Magazine Series 5, 46:280, 312-338, DOI: 10.1080/14786449808621199

To link to this article: http://dx.doi.org/10.1080/14786449808621199

曲 Published online: 08 May 2009.

Submit your article to this journal $[\pi$

Џ Article views: 2

Q View related articles $\asymp$ 


\section{[ 312 ]}

XXX. A Quantitative Study of the High-Frequency InductionCoil. By W. P. Bornton *.

THE behaviour of eircuits containing self- and mutualinduction, and some of the properties of the disruptive discharge of a leyden-jar, were experimentally investigated by Faraday $\dagger$ and Joseph Henry $\ddagger$. The latter, besides studying the action of two mutually inducing coils, one of which was traversed by the current from a galvanic battery, also discharged a leyden-jar through one coil and noted the currents induced in the neighbouring coil $\S$. Henry also noted phenomena in the discharge of the Leyden jar from which he concluded that this must be oscillatory in character \|.

Perhaps the first direct experimental verification of the oscillatory character of this discharge was made by lieddersen in the years $1857-62^{* *}$, by observing the spark in a revolving mirror.

The mathematical theory of the oscillatory discharge was given by Lord Kelvin $\dagger \dagger$ and Kirchhoff $\ddagger \neq$. The general theory of electrical oscillations has been discussed at more or less length, particularly by J. J. Thomson $\S \S$.

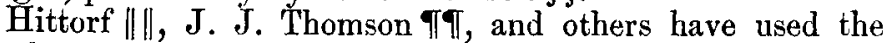
discharge of a leyden-jar through a coil of wire about a vacuum tube as a means of studying the behaviour of the rarefied gas. Within the present decade many have repeated Henry's experiment of discharging a condenser through one coil of wire and studying the effect produced in a secondary circuit. Many ${ }^{* *}$ have paid particular attention

* Communicated by Prof. A. G. Webster.

$\dagger$ Experimental Researches: Series I. Induction of Electric Currents ; Series XII. The Disruptive Discharge.

† Smithsonian Miscellaneous Collections - Scientific Writings of Joseph Henry : Contributions to Electricity and Magnetism, iii. (1838) p. 108, \& iv. (1840), "On Electromagnetic Induction;" v. (1842) p. 200 , "On Electrostatic Induction and the Oscillatory Discharge."

$\S$ Ibid. pp. 132 et seq. $\|$ Ibid. p. 200.

** Pogg. Ann. ciii. p. 69 (1858), cviii. p. 497 (1859), cxii. p. 452 (1861), cxili. p. 437 (1861), cxvi. p. 132 (1862).

t† Phil. Mag. (4) v. p. 393 (1853); Math. and Phys. Papers, vol. i. p. 540 .

¥t Pogg. Ann. cxxi. p. 551 (1864); Ges. Abh. p. 168.

$\$ \S$ Recent Researches in Electricity and Magnetism, chap. iv. p. 251.

inl Wied. Ann. xxi. p. 90 (1864).

II Proc. Roy. Soc. xlv. p. 269 (1869); Recent Researches, p. 92.

*** Nikola Tesla, Electrical Engineer (N.Y.), xii. p. 35 (1891), xv. pp. 42, 65, 88, 531, 553, 579, 603, 626 (1893); published also in book form. Elihu Thomson, Elec. Eng. xiii. pp. 159, 199 (1892). H. Ebert, Wied. Ann. liii. p. 144 (1894). Elster, 10. Jahresber. des Ver. f. Naturw. zu Braunschweig, p. 43 (1895); Wied. Beibl. xx. p. 338 (1896). 
to the phenomena of the varying electrostatic field; while some have attempted to follow the behaviour of the current in one of the circuits. Colley ${ }^{*}$ has accomplished this by making the period very slow and using an "oscillometer"-either a fluctuating flame or the mirror of an exceedingly sensitive galvanometer.

\section{Theoretical.}

The mathematical theory of the so-called Tesla coil has been discussed by Oberbeck and others $\dagger$. The discussion which follows is a modification and extension of Oberbeck's. It is essentially a discussion of a system with two degrees of freedom.

Let the suffixes 1 and 2 refer to the primary and secondary circuits respectively. Let $\mathrm{V}$ represent the difference of potential at the terminals of the condenser, I the current, $Q$ the charge on the condenser, L self-induction, M mutualinduction, $K$ capacity, $R$ resistance. We have then to distinguish two cases :-(1) The secondary cireuit is open; that is, is closed by a capacity. (2) The secondary circuit is closed by a resistance, or short-circuited.

(1) The differential equations of the system are :-

$$
\begin{aligned}
& \mathrm{V}_{1}+\mathrm{L}_{1} \frac{d \mathrm{I}_{1}}{d t}+\mathrm{M} \frac{d \mathrm{I}_{2}}{d t}+\mathrm{R}_{1} \mathrm{I}_{1}=0 \\
& \mathrm{~V}_{2}+\mathrm{L}_{2} \frac{d \mathrm{I}_{2}}{d t}+\mathrm{M} \frac{d \mathrm{I}_{1}}{d t}+\mathrm{R}_{2} \mathrm{I}_{2}=0
\end{aligned}
$$

Making use of the equations of continuity,

and of charge,

$$
\mathrm{I}=\frac{d \mathrm{Q}}{d t},
$$

$$
\mathrm{V}=\frac{\mathrm{Q}}{\mathrm{K}}
$$

these become

$$
\begin{aligned}
& \frac{\mathrm{Q}_{1}}{\mathrm{~K}_{1}}+\mathrm{L}_{1} \frac{d^{2} \mathrm{Q}_{1}}{d t^{2}}+\mathrm{M} \frac{d^{2} \mathrm{Q}_{2}}{d t^{2}}+\mathrm{R}_{1} \frac{d \mathrm{Q}_{1}}{d t}=0 \\
& \frac{\mathrm{Q}_{2}}{\mathrm{~K}_{2}}+\mathrm{L}_{2} \frac{d^{2} \mathrm{Q}_{2}}{d t^{2}}+\mathrm{M} \frac{d^{2} \mathrm{Q}_{1}}{d t^{2}}+\mathrm{R}_{2} \frac{d \mathrm{Q}_{2}}{d t}=0 .
\end{aligned}
$$

* Wied. Ann. xxvi. p. 432 (1885), xxviii. p. 1 (1886), xliv. p. 102 (1891). See also Hotchkiss and Millis, Phys. Rev. iii. p. 49 (189ō).

† Oberbeck, Wied. Ann. lv. p. 623 (1825). Domalip and Kolácek, Wied. Ann. lvii. p. 731 (1896). Blümcke, Wied. Ann. lviii. p. 405 (1896). Wien, Wied. Ann. lxi. p. 151 (1897), gires the mathematical theory for two circuits in the general case, where they have not only mutual induction, but also mutual capacity and "mutual resistance"-that is, affect the distribution of the current in the bodies of the conductors. 
Assuming that the solutions are of the form

$$
\mathrm{Q}_{1}=e^{\lambda t}, \quad \mathrm{Q}_{2}=k e^{\lambda t},
$$

our equations become

$$
\begin{aligned}
1+\mathrm{L}_{1} \mathrm{~K}_{1} \lambda^{2}+k \mathrm{MK}_{1} \lambda^{2}+\mathrm{R}_{1} \mathrm{~K}_{1} \lambda & =0 \\
k+k \mathrm{~L}_{2} \mathrm{~K}_{2} \lambda^{2}+\mathrm{MK}_{2} \lambda^{2}+k \mathrm{R}_{2} \mathrm{~K}_{2} \lambda & =0 .
\end{aligned}
$$

Solving for $k$,

$$
k=-\frac{1+\mathrm{L}_{1} \mathrm{~K}_{1} \lambda^{2}+\mathrm{R}_{1} \mathrm{~K}_{1} \lambda}{M \mathrm{~K}_{1} \lambda^{2}}=-\frac{\mathrm{MK}_{2} \lambda^{2}}{1+\mathrm{L}_{2} \mathrm{~K}_{2} \lambda^{2}+\mathrm{R}_{2} \mathrm{~K}_{2} \lambda} .
$$

Clearing of fractions, collecting, and dividing by the coefficient of $\lambda^{4}$,

$$
\begin{aligned}
& \lambda^{4}+\lambda^{3} \frac{\mathrm{L}_{1} \mathrm{R}_{2}+\mathrm{L}_{2} \mathrm{R}_{1}}{\mathrm{~L}_{1} \mathrm{~L}_{2}-\mathrm{M}^{2}}+\lambda^{2} \frac{\mathrm{L}_{1} \mathrm{~K}_{1}+\mathrm{L}_{2} \mathrm{~K}_{2}+\mathrm{R}_{1} \mathrm{R}_{2} \mathrm{~K}_{1} \mathrm{~K}_{2}}{\mathrm{~K}_{1} \mathrm{~K}_{2}\left(\mathrm{~L}_{1} \mathrm{~L}_{2}-\mathrm{M}^{2}\right)} \\
&+\lambda \frac{\mathrm{R}_{1} \mathrm{~K}_{1}+\mathrm{R}_{2} \mathrm{~K}_{2}}{\mathrm{~K}_{1} \mathrm{~K}_{2}\left(\mathrm{~L}_{1} \mathrm{~L}_{2}-\mathrm{M}^{2}\right)}+\frac{1}{\mathrm{~K}_{1} \mathrm{~K}_{2}\left(\mathrm{~L}_{1} \mathrm{~L}_{2}-\mathrm{M}^{2}\right)}=0,
\end{aligned}
$$

which is of the fourth degree in $\lambda$. We are interested in the imaginary roots, which occur, if at all, in conjugate pairs, since the coefficients of our equation are all real. If we write these

$$
\begin{array}{ll}
\lambda_{1}=-\alpha+i \beta, & \lambda_{3}=-\gamma+i \delta, \\
\lambda_{2}=-\alpha-i \beta, & \lambda_{4}=-\gamma-i \delta,
\end{array}
$$

then by the theory of equations

$$
\begin{aligned}
& -\left(\lambda_{1}+\lambda_{2}+\lambda_{3}+\lambda_{4}\right)=2 \alpha+2 \gamma=\frac{\mathrm{L}_{2} \mathrm{R}_{1}+\mathrm{L}_{1} \mathrm{R}_{2}}{\mathrm{~L}_{1} \mathrm{~L}_{2}-\mathrm{M}^{2}}=\mathrm{A}, \\
& \Sigma \lambda_{r} \lambda_{s}=\lambda_{1} \lambda_{2}+\lambda_{3} \lambda_{4}+\left(\lambda_{1}+\lambda_{2}\right)\left(\lambda_{3}+\lambda_{4}\right) \\
& (r \neq s) \quad=\alpha^{2}+\beta^{2}+\gamma^{2}+\delta^{2}+4 \alpha \gamma \\
& =\frac{\mathrm{L}_{1} \mathrm{~K}_{1}+\mathrm{L}_{2} \mathrm{~K}_{2}+\mathrm{R}_{1} \mathrm{R}_{2} \mathrm{~K}_{1} \mathrm{~K}_{2}}{\mathrm{~K}_{1} \mathrm{~K}_{2}\left(\mathrm{~L}_{1} \mathrm{~L}_{2}-\mathrm{M}^{2}\right)}=\mathrm{B}, \text {. . } \\
& -\Sigma \lambda_{r} \lambda_{8} \lambda_{t}=-\left(\lambda_{1}+\lambda_{2}\right) \lambda_{3} \lambda_{4}-\left(\lambda_{3}+\lambda_{4}\right) \lambda_{1} \lambda_{2} \\
& (r \neq s \neq t) \quad=2 \alpha\left(\gamma^{2}+\delta^{2}\right)+2 \gamma\left(\alpha^{2}+\beta^{2}\right) \\
& =\frac{\mathrm{R}_{1} \mathrm{~K}_{1}+\mathrm{R}_{2} \mathrm{~K}_{2}}{\mathrm{~K}_{1} \mathrm{~K}_{2}\left(\mathrm{~L}_{1} \mathrm{~L}_{2}-\mathrm{M}^{2}\right)}=\mathrm{C}, . . . . \\
& \lambda_{1} \lambda_{2} \lambda_{3} \lambda_{4}=\left(\alpha^{2}+\beta^{2}\right)\left(\gamma^{2}+\delta^{2}\right) \\
& =\frac{1}{\mathrm{~K}_{1} \overline{\mathrm{K}}_{2}\left(\mathrm{~L}_{1} \mathrm{~L}_{2}-\overline{\mathrm{M}}^{2}\right)}=\mathrm{D} . \quad . \quad . \quad \text {. }
\end{aligned}
$$


From (3) and (5), disregarding $4 a y$ as small, we get

$$
\alpha^{2}+\beta^{2}=\frac{\mathrm{B}+\sqrt{\mathrm{B}^{2}-4 \mathrm{D}}}{2}, \quad \gamma^{2}+\delta^{2}=\frac{\mathrm{B}-\sqrt{\mathrm{B}^{2}-4 \mathrm{D}}}{2} ;
$$

and from these and (2) and (4)

$$
\alpha=\frac{\mathrm{A}}{4}+\frac{\mathrm{AB}-2 \mathrm{O}}{4 \sqrt{\mathrm{B}^{2}-4 \mathrm{D}}}, \quad \gamma=\frac{\mathrm{A}}{4}-\frac{\mathrm{AB}-2 \mathrm{C}}{4 \sqrt{\mathrm{B}^{2}-4 \mathrm{I}}} .
$$

By making the proper substitutions, these become

$$
\begin{aligned}
& \alpha^{2}+\beta^{2}=\frac{\mathrm{L}_{1} \mathrm{~K}_{1}+\mathrm{L}_{2} \mathrm{~K}_{2}+\sqrt{\left(\mathrm{L}_{1} \mathrm{~K}_{1}-\mathrm{L}_{2} \mathrm{~K}_{2}\right)^{2}+4 \mathrm{M}^{2} \mathrm{~K}_{1} \mathrm{~K}_{2}}}{2 \mathrm{~K}_{1} \mathrm{~K}_{2}\left(\mathrm{~L}_{1} \mathrm{~L}_{2}-\mathrm{M}^{2}\right)} ; \\
& \gamma^{2}+\delta^{2}=\frac{\mathrm{L}_{1} \mathrm{~K}_{1}+\mathrm{L}_{2} \mathrm{~K}_{2}-\sqrt{\left(\mathrm{L}_{1} \bar{K}_{1}-\mathrm{L}_{2} \mathrm{~K}_{2}\right)^{2}+4 \mathrm{M}^{2} \bar{K}_{1} \mathrm{~K}_{2}}}{2 \mathrm{~K}_{1} \mathrm{~K}_{2}\left(\mathrm{~L}_{1} \mathrm{~L}_{2}-\bar{M}^{2}\right)} ; \\
& R_{1}\left[L_{2}\left(L_{1} K_{1}+L_{2} K_{2}\right)-2 K_{1}\left(L_{1} L_{2}-M^{2}\right)\right] \\
& \alpha=\frac{\mathrm{R}_{1} \mathrm{~L}_{2}+\mathrm{R}_{2} \mathrm{~L}_{1}+\frac{+\mathrm{R}_{2}\left[\mathrm{~L}_{1}\left(\mathrm{~L}_{1} \mathrm{~K}_{1}+\mathrm{L}_{2} \mathrm{~K}_{2}\right)-2 \mathrm{~K}_{2}\left(\mathrm{~L}_{1} \mathrm{~L}_{2}-\mathrm{M}^{2}\right)\right]}{\sqrt{\left(\mathrm{I}_{1} \mathrm{~K}_{1}-\mathrm{L}_{2} \mathrm{~K}_{2}\right)^{2}+4 \mathrm{M}^{2} \mathrm{~K}_{1} \mathrm{~K}_{2}}}}{4\left(\mathrm{~L}_{1} \mathrm{~L}_{2}-\mathrm{M}^{2}\right)} ;
\end{aligned}
$$

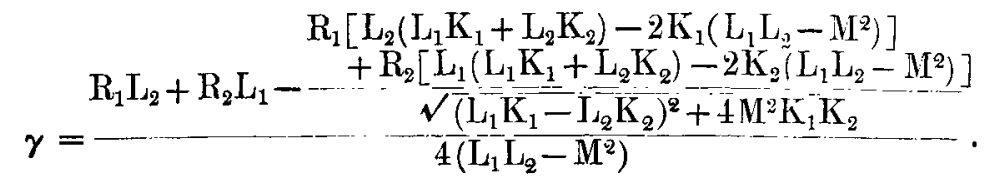
form

The general solution may now be written in exponential

$$
\begin{aligned}
& \mathrm{Q}_{2}=\mathrm{E} e^{\lambda_{1} t}+\mathrm{F} e^{\lambda_{2} t}+\mathrm{G} e^{\lambda_{3} t}+\mathrm{H} e^{\lambda_{4} t}, \\
& \mathrm{Q}_{2}=k_{1} \mathrm{E} e^{\lambda_{1} t}+k_{2} \mathrm{~F} e^{\lambda_{2} t}+k_{3} \mathrm{G} e^{\lambda_{3} t}+k_{4} \mathrm{H} e^{\lambda_{1} t},
\end{aligned}
$$

which reduces to the trigonometrical form

$$
\begin{aligned}
& \begin{array}{r}
\mathrm{Q}_{1}=e^{-\alpha t}[(\mathrm{E}+\mathrm{F}) \cos \beta t+i(\mathrm{E}-\mathrm{F}) \sin \beta t] \\
+e^{-\gamma t}[(\mathrm{G}+\mathrm{H}) \cos \delta t+i(\mathrm{G}-\mathrm{H}) \sin \delta t]
\end{array} \\
& \begin{array}{r}
\mathrm{Q}_{2}=e^{-\alpha t}\left[\left(k_{1} \mathrm{E}+k_{2} \mathrm{~F}\right) \cos \beta t+i\left(k_{1} \mathrm{E}-k_{2} \mathrm{~F}\right) \sin \beta t\right] \\
\quad+e^{-\gamma t}\left[\left(k_{3} \mathrm{G}+k_{4} \mathrm{H}\right) \cos \delta t+i\left(k_{3} \mathrm{G}-k_{4} \mathrm{H}\right) \sin \delta t\right] ;
\end{array}
\end{aligned}
$$

or otherwise

$$
\begin{aligned}
& \mathrm{Q}_{1}=e^{-\alpha t}\left(\mathrm{~A}_{1} \cos \beta t+\mathrm{B}_{1} \sin \beta t\right)+e^{-\gamma t}\left(\mathrm{C}_{1} \cos \delta t+\mathrm{D}_{1} \sin \delta t\right), \\
& \mathrm{Q}_{2}=e^{-\alpha t}\left(\mathrm{~A}_{2} \cos \beta t+\mathrm{B}_{2} \sin \beta t\right)+e^{-\gamma t}\left(\mathrm{C}_{2} \cos \delta t+\mathrm{D}_{2} \sin \delta t\right) .
\end{aligned}
$$

Equating the coefficients of corresponding terms, elimi- 
nating $\mathrm{E}, \mathrm{F}, \mathrm{G}, \mathrm{H}$, and noting that we may write

$$
\left.\begin{array}{ll}
k_{1}=a+b i, & k_{3}=c+d i, \\
k_{2}=a-b i, & k_{4}=c-d i,
\end{array}\right\} . . . .
$$

we obtain the four relations

$$
\left.\begin{array}{ll}
a \mathrm{~A}_{1}+b \mathrm{~B}_{1}=\mathrm{A}_{2}, & -b \mathrm{~A}_{1}+a \mathrm{~B}_{1}=\mathrm{B}_{2}, \\
c \mathrm{C}_{1}+d \mathrm{D}_{1}=\mathrm{C}_{2}, & -d \mathrm{C}_{1}+a \mathrm{D}_{1}=\mathrm{D}_{2},
\end{array}\right\} .
$$

The initial conditions that when $t=0$,

$$
\mathrm{Q}_{1}=\mathrm{V}_{1} \mathrm{~K}_{1}=\mathrm{V}_{0} \mathrm{~K}_{1}, \quad \frac{d \mathrm{Q}_{1}}{d t}=0, \quad \mathrm{Q}_{2}=0, \quad \frac{d \mathrm{Q}_{2}}{d t}=0,
$$

give the four equations

$$
\left.\begin{array}{ll}
\mathrm{A}_{1}+\mathrm{C}_{1}=\mathrm{V}_{0} \mathrm{~K}_{1}, & -\alpha \mathrm{A}_{1}+\beta \mathrm{B}_{1}-\gamma \mathrm{C}_{1}+\delta \mathrm{D}_{1}=0, \\
\mathrm{~A}_{2}+\mathrm{C}_{2}=0, & -\alpha \mathrm{A}_{2}+\beta \mathrm{B}_{2}-\gamma \mathrm{C}_{2}+\delta \mathrm{D}_{2}=0,
\end{array}\right\}
$$

which suffice with equations (13) to determine all the eight constants.

If from equations (14) we eliminate $A_{2}, B_{2}, C_{2}, D_{2}$ by equations (13) we have four equations in $A_{1}, B_{1}, C_{1}, D_{1}$ :

$$
\left.\begin{array}{c}
\mathrm{A}_{1}+\mathrm{C}_{1}=\mathrm{V}_{0} \mathrm{~K}_{1}, \\
a \mathrm{~A}_{1}+b \mathrm{~B}_{1}+c \mathrm{C}_{1}+d \mathrm{D}_{1}=0, \\
-a \mathrm{~A}_{1}+\beta \mathrm{B}_{1}-\gamma \mathrm{C}_{1}+\delta \mathrm{D}_{1}=0, \\
(\alpha a+\beta b) \mathrm{A}_{1}+(\alpha b-\beta a) \mathrm{B}_{1}+(\gamma c+\delta d) \mathrm{C}_{1}+(\gamma d-\delta c) \mathrm{D}_{1}=0,
\end{array}\right\}
$$

whose determinant is

$\Delta=\beta \delta\left(\alpha^{2}+b^{2}+c^{2}+d^{2}\right)-b d\left(\alpha^{2}+\beta^{2}+\gamma^{2}+\delta^{2}\right)+2 a \gamma b d-2 \beta \delta a c$, and their solution

$$
\left.\begin{array}{l}
\mathrm{A}_{1}=\frac{\mathrm{V}_{0} \mathrm{~K}_{1}\left[\beta \delta\left(c^{2}+d^{2}\right)-b d\left(\gamma^{2}+\delta^{2}\right)+(\alpha b-\beta a)(\gamma d+\delta c)\right]}{\Delta}, \\
\mathrm{B}_{1}=\frac{\mathrm{V}_{0} \mathrm{~K}_{1}\left[\alpha \delta\left(c^{2}+d^{2}\right)+a d\left(\gamma^{2}+\delta^{2}\right)-(\alpha a+\beta b)(\gamma d+\delta c)\right]}{\Delta}, \\
\mathrm{C}_{1}=\frac{\mathrm{V}_{0} \mathrm{~K}_{1}\left[\beta \delta\left(a^{2}+b^{2}\right)-b d\left(\alpha^{2}+\beta^{2}\right)+(\alpha b+\beta a)(\gamma d-\delta c)\right]}{\Delta}, \\
\mathrm{D}_{1}=\frac{\mathrm{V}_{0} \mathrm{~K}_{1}\left[\beta \gamma\left(a^{2}+b^{2}\right)+b c\left(\alpha^{2}+\beta^{2}\right)-(\alpha b+\beta a)(\gamma c+\delta d)\right]}{\Delta},
\end{array}\right\}
$$

Or, if we disregard the squares of the small quantities $\alpha, \gamma$, $b, d\left(\frac{b}{g}\right.$ is of the order of $\left.\frac{\alpha}{\beta}, \& c.\right)$, 


$$
\begin{aligned}
& \Delta=\beta \delta(a-c)^{2} ; \\
& \mathrm{A}_{1}=\frac{\mathrm{V}_{0} \mathrm{~K}_{1} \beta \delta\left(c^{2}-a c\right)}{\Delta}=\frac{\mathrm{V}_{0} \mathrm{~K}_{1} c}{c-a} ; \\
& \mathrm{B}_{1}=\frac{\mathrm{V}_{0} \mathrm{~K}_{1}\left[a \delta c^{2}+a d \delta^{2}-\delta c(\alpha a+\beta b)\right]}{\Delta} \\
& \mathrm{C}_{1}=\frac{\mathrm{V}_{0} \mathrm{~K}_{1} \beta \delta\left(a^{2}-a c\right)}{\Delta}=\frac{\mathrm{V}_{0} \mathrm{~K}_{1} a}{a-c} ; \\
& \mathrm{D}_{1}=\frac{\mathrm{V}_{0} \mathrm{~K}_{1}\left[\beta \gamma a^{2}+b c \beta^{2}-\beta a(\gamma c+\delta d)\right]}{\Delta}
\end{aligned}
$$

where $B_{1}$ and $D_{1}$ are small of the first order in comparison with $\mathrm{A}_{1}$ and $\mathrm{C}_{1}$.

$a$ and $b$ of equation (12) are the real part and the coefficient of the imaginary part of $k_{1}$ respectively. From (1) we have

$$
\begin{aligned}
k_{1} & =-\frac{1+\mathrm{L}_{1} \mathrm{~K}_{1} \lambda_{1}{ }^{2}+\mathrm{R}_{1} \mathrm{~K}_{1} \lambda_{1}}{\mathrm{MK}_{1} \lambda_{1}{ }^{2}}=-\frac{1+\mathrm{L}_{1} \mathrm{~K}_{1}(-\alpha+i \beta)^{2}+\mathrm{R}_{1} \mathrm{~K}_{1}(-\alpha+i \beta)}{\mathrm{MK}_{1}(-\alpha+i \beta)^{2}} \\
& =-\frac{(-\alpha-i \beta)^{2}+\mathrm{L}_{1} \frac{\mathrm{K}_{1}\left(\alpha^{2}+\beta^{2}\right)^{2}+\mathrm{R}_{1} \mathrm{~K}_{1}(-\alpha-i \beta)\left(\alpha^{2}+\beta^{2}\right)}{\mathrm{MK}_{1}\left(\alpha^{2}+\beta^{2}\right)^{2}}}{}
\end{aligned}
$$

from which we get

$$
\begin{aligned}
& a=-\frac{a^{2}-\beta^{2}+\mathrm{L}_{1} \mathrm{~K}_{1}\left(\alpha^{2}+\beta^{2}\right)^{2}-\mathrm{R}_{1} \mathrm{~K}_{1} \alpha\left(\alpha^{2}+\beta^{2}\right)}{\mathrm{MK}_{1}\left(\alpha^{2}+\beta^{2}\right)^{2}} ; \\
& b=-\frac{2 \alpha \beta-\mathrm{R}_{1} \mathrm{~K}_{1} \beta\left(\alpha^{2}+\beta^{2}\right)}{\operatorname{MK}_{1}\left(\alpha^{2}+\beta^{2}\right)^{2}} .
\end{aligned}
$$

If $\alpha$ is so small that we may disregard its square in comparison with $\beta^{2}$, these become

$$
\left.\begin{array}{l}
a=\frac{1-\mathrm{L}_{1} \mathrm{~K}_{1} \beta^{2}}{\mathrm{MK}_{1} \beta^{2}}=\frac{\delta^{2}-\mathrm{L}_{1} \mathrm{~K}_{1} \beta^{2} \delta^{2}}{\mathrm{MK}_{1} \beta^{2} \delta^{2}} ; \\
b=\frac{\mathrm{R}_{1} \mathrm{~K}_{1} \beta^{2}-2 \alpha}{\mathrm{MK}_{1} \beta^{3}} ;
\end{array}\right\} .
$$

and by substituting $\gamma$ and $\delta$ for $\alpha$ and $\beta$,

$$
\left.\begin{array}{l}
c=\frac{1-\mathrm{L}_{1} \mathrm{~K}_{1} \delta^{2}}{\mathrm{MK}_{1} \delta^{2}}=\frac{\beta^{2}-\mathrm{L}_{1} \mathrm{~K}_{1} \beta^{2} \delta^{2}}{M \mathrm{~K}_{1} \beta^{2} \delta^{2}} ; \\
d=\frac{\mathrm{R}_{1} \mathrm{~K}_{1} \delta^{2}-2 \gamma}{\mathrm{MK}_{1} \delta^{3}} .
\end{array}\right\} .
$$

Substituting the values of $\beta$ and $\delta$, we get for $a$ and $c$

$$
\begin{aligned}
& a=\frac{\mathrm{L}_{2} \mathrm{~K}_{2}-\mathrm{I}_{1} \mathrm{~K}_{1}-\sqrt{\left(\mathrm{L}_{1} \mathrm{~K}_{1}-\mathrm{L}_{2} \mathrm{~K}_{2}\right)^{2}+4 \mathrm{M}^{2} \mathrm{~K}_{1} \mathrm{~K}_{2}}}{2 \mathrm{MK}_{1}} ; \\
& c=\frac{\mathrm{L}_{2} \mathrm{~K}_{2}-\mathrm{L}_{1} \mathrm{~K}_{1}+\sqrt{\left(\mathrm{L}_{1} \mathrm{~K}_{1}-\mathrm{L}_{2} \mathrm{~K}_{2}\right)^{2}+4 \mathrm{M}^{2} \mathrm{~K}_{1} \mathrm{~K}_{2}}}{2 \mathrm{M} \mathrm{K}_{1}} .
\end{aligned}
$$


Substituting these values in equation (17), we have

$$
\mathrm{A}_{1}=\frac{1-\chi}{2} \nabla_{0} \mathrm{~K}_{1} ; \quad \mathrm{C}_{1}=\frac{1+\chi}{2} \mathrm{~V}_{0} \mathrm{~K}_{1}, \ldots .
$$

where

and

$$
\chi=\frac{\mathrm{L}_{1} \mathrm{~K}_{1}-\mathrm{L}_{2} \mathrm{~K}_{2}}{\sqrt{\left(\mathrm{L}_{1} \mathrm{~K}_{1}-\mathrm{L}_{2} \overline{\mathrm{K}}_{2}\right)^{2}+4 \overline{\mathrm{M}}^{2} \overline{\mathrm{K}}_{1} \mathrm{~K}}} ;
$$

$$
-\mathrm{A}_{2}=\mathrm{C}_{2}=\frac{a c}{a-c} \nabla_{0} \mathrm{~K}_{1}=\frac{\mathrm{MK}_{1} \mathrm{~K}_{2} \mathrm{~V}_{0}}{\sqrt{\left(\mathrm{L}_{1} \mathrm{~K}_{1}-\mathrm{L}_{2} \overline{\mathrm{K}}_{2}\right)^{2}+4 \mathrm{M}^{2}} \overline{\mathrm{K}_{1} \mathrm{~K}_{2}}} ;
$$

$B_{2}$ and $D_{2}$ are small of the first order in comparison with $A_{2}$ and $\mathrm{C}_{2}$.

(2) If the secondary circuit be closed, $\mathrm{V}_{2}$ drops out, or $\mathrm{K}$ may be considered infinite, and our equation (1) becomes

whence

$$
k=-\frac{1+\mathrm{I}_{1} \mathrm{~K}_{1} \lambda^{2}+\mathrm{R}_{1} \mathrm{~K}_{1} \lambda}{M \mathrm{~K}_{1} \lambda^{2}}=-\frac{\mathrm{M} \lambda^{2}}{\mathrm{~L}_{2} \lambda^{2}+\mathrm{R}_{2} \lambda}=-\frac{\mathrm{M} \lambda}{\mathrm{L}_{2} \lambda+\mathrm{R}_{2}}
$$

$$
\lambda_{1}=-\alpha+i \beta, \quad \lambda_{2}=-\alpha-i \beta, \quad \lambda_{3}=-\gamma,
$$

where

$$
\begin{aligned}
& \left.\begin{array}{l}
\alpha=\frac{1}{2}\left[\frac{\mathrm{L}_{1} \mathrm{R}_{2}+\mathrm{L}_{2} \mathrm{R}_{1}}{\mathrm{~L}_{1} \mathrm{~L}_{2}-\mathrm{M}^{2}}-\frac{\mathrm{R}_{2}}{\mathrm{~L}_{2}}\right]=\frac{\mathrm{L}_{2}{ }^{2} \mathrm{R}_{1}+\mathrm{M}^{2} \mathrm{R}_{2}}{2 \mathrm{~L}_{2}\left(\mathrm{~L}_{1} \mathrm{~L}_{2}-\mathrm{M}^{2}\right)} ; \\
\beta=\sqrt{\frac{\mathrm{I}_{2}}{\mathrm{~K}\left(\mathrm{~L}_{1} \mathrm{~L}_{2}-\mathrm{M}^{2}\right)}} ; \quad \gamma=\frac{\mathrm{R}_{2}}{\mathrm{~L}_{2}} .
\end{array}\right\} . \\
& a=-\frac{\mathrm{M}}{\mathrm{L}_{2}} \\
& b=\beta\left[\frac{\mathrm{R}_{1} \mathrm{~K}\left(\mathrm{~L}_{1} \mathrm{~L}_{2}-\mathrm{M}^{2}\right)}{\mathrm{ML}_{2}}-\frac{2 \alpha \mathrm{K}\left(\mathrm{L}_{1} \mathrm{~L}_{2}-\mathrm{M}^{2}\right)^{2}}{\mathrm{ML}_{2}{ }^{2}}\right]=-\beta \frac{\mathrm{R}_{2} \mathrm{MK}\left(\mathrm{L}_{1} \mathrm{~L}_{2}-\mathrm{M}^{2}\right)}{\mathrm{L}_{2}{ }^{3}}, \\
& \mathrm{C}=-\frac{\mathrm{L}_{2}{ }^{2}}{\mathrm{R}_{2}{ }^{2} \mathrm{MK}} \text {. }
\end{aligned}
$$

The general solution may be written

$$
\begin{aligned}
& \mathrm{Q}_{1}=e^{-\alpha t}\left(\mathrm{~A}_{1} \cos \beta t+\mathrm{B}_{1} \sin \beta t\right)+\mathrm{C}_{1} e^{-\gamma t}, \\
& \mathrm{Q}_{2}=e^{-\alpha t}\left(\mathrm{~A}_{2} \cos \beta t+\mathrm{B}_{2} \sin \beta t\right)+\mathrm{C}_{2} e^{-\gamma t},
\end{aligned}
$$

where the constants are related by the equations

$$
\begin{aligned}
a \mathrm{~A}_{1}+b \mathrm{~B}_{1} & =\mathrm{A}_{2}, \\
a \mathrm{~B}_{1}+b \mathrm{~A}_{1} & =\mathrm{B}_{2}, \\
c \mathrm{C}_{1} & =\mathrm{C}_{2} .
\end{aligned}
$$


And subject to the initial conditions that when $t=0$,

$$
\nabla_{1}=\nabla_{0}, \quad \frac{d \nabla_{1}}{d t}=0, \quad \mathrm{I}_{2}=0,
$$

or

$$
\begin{aligned}
\mathrm{A}_{1}+\mathrm{C}_{1} & =\mathrm{V}_{0} \mathrm{~K}, \\
-\alpha \mathrm{A}_{1}+\beta \mathrm{B}_{1}-\gamma \mathrm{C}_{1} & =0, \\
-\alpha \mathrm{A}_{2}+\beta \mathrm{B}_{2}-\gamma \mathrm{C}_{2} & =0,
\end{aligned}
$$

which completely determine the constants. Substituting the values of $A_{2}, B_{2}, C_{2}$ in the last equation, we get

$$
\left.\begin{array}{rr}
\mathrm{A}_{1} & +\mathrm{C}_{1}=\mathrm{V}_{0} \mathrm{~K} \\
-\alpha \mathrm{A}_{1}+\beta \mathrm{B}_{1}-\gamma \mathrm{C}_{1}=0, \\
(\alpha a+\beta b) \mathrm{A}_{1}+(\alpha b-\beta a) \mathrm{B}_{1}+\gamma c \mathrm{C}_{1}=0,
\end{array}\right\}
$$

whose determinant is

$$
\begin{aligned}
& \Delta=-b\left(\alpha^{2}+\beta^{2}-\alpha \gamma\right)+\beta \gamma(c-a) . \\
\mathrm{A}_{1}= & \frac{\mathrm{V}_{0} \mathrm{~K}}{\Delta} \gamma(\beta c+\alpha b-\beta a), \\
\mathrm{B}_{1}= & \frac{\mathrm{V}_{0} \mathrm{~K}}{\Delta} \gamma(\alpha c-\alpha a-\beta b), \\
\mathrm{C}_{1}= & \frac{\mathrm{V}_{0} \mathrm{~K}}{\Delta} b\left(-\alpha^{2}-\beta^{2}\right), \\
\mathrm{A}_{2}= & \frac{\mathrm{V}_{0} \mathrm{~K}}{\Delta} \gamma\left[c(\alpha b+\beta a)-\beta\left(a^{2}+b^{2}\right)\right], \\
\mathrm{B}_{2}= & \frac{\mathrm{V}_{0} \mathrm{~K}}{\Delta} \gamma\left[c(\alpha a-\beta b)-\alpha\left(a^{2}+b^{2}\right)\right], \\
\mathrm{C}_{2}= & \frac{\mathrm{V}_{0} \mathrm{~K}}{\Delta} b c\left(-\alpha^{2}-\beta^{2}\right) .
\end{aligned}
$$

The quantities which are observable and measurable in the ordinary type of instruments are not the instantaneous potentials and currents whose values we have just deduced, but the "effective" values, that is, the square roots of the mean squares. It is desirable then to evaluate an integral of the form $\int V^{2} d t$ for the case of a single-damped oscillation, and also for two superposed oscillations. By giving the proper values to certain constants this will include all the cases which we shall need to consider.

(a) The general exponential form for an oscillation of any amplitude and period is

$$
\mathrm{V}=\mathrm{E} e^{\lambda t}+\mathrm{F} e^{\mu t},
$$


where $\mathbf{E}$ and $\mathbf{F}$ may be complex, and

$$
\lambda=-\alpha+\beta i, \quad \mu=-\alpha-\beta i,
$$

where $\alpha$ and $\beta$ are real and greater than 0 .

Then

$$
\begin{aligned}
\int \mathrm{V}^{2} d t & =\mathrm{E}^{2} \int e^{2 \lambda t} d t+\mathrm{F}^{2} \int e^{2 \mu t} d t+2 \mathrm{EF} \int e^{(\lambda+\mu) t} d t \\
& =\frac{\mathrm{E}^{2} e^{2 \lambda t}}{2 \lambda}+\frac{\mathrm{F}^{2} e^{2 \mu t}}{2 \mu}+\frac{2 \mathrm{EF} e^{(\lambda+\mu) t}}{\lambda+\mu} \\
& =\frac{\mathrm{E}^{2} \mu e^{2 \lambda t}+\mathrm{F}^{2} \lambda e^{2 \mu t}}{2 \lambda \mu}+\frac{2 \mathrm{EF} e^{(\lambda+\mu) t}}{\lambda+\mu}
\end{aligned}
$$

where all the denominators are real, or in terms of $\alpha$ and $\beta$

$$
\begin{aligned}
& e^{-2 a t}\left\{\left[E^{2}(-\alpha+\beta i)+F^{2}(-\alpha-\beta i)\right] \cos 2 \beta t\right. \\
& =\frac{\left.+i\left[\mathrm{E}^{3}(-\alpha+\beta i)-\mathrm{F}^{2}(-\alpha-\beta i)\right] \sin 2 \beta t\right\}}{2\left(\alpha^{2}+\beta^{2}\right)} \\
& +\frac{2 \mathrm{EF} e^{-2 \alpha t}}{-2 \alpha}
\end{aligned}
$$

Since the oscillation is real, $\mathrm{V}=e^{-\alpha t}[(\mathrm{E}+\mathrm{F}) \cos \beta t+i(\mathrm{E}-\mathrm{F}) \sin \beta t] \equiv e^{-\alpha t}(\mathrm{~A} \cos \beta t+\mathrm{B} \sin \beta t) ;$ substituting $A$ and $B$ from this identity, the imaginary parts vanish, and

$$
\begin{aligned}
& e^{-2 a t}\left[\left\{\left(\mathrm{~B}^{2}-\mathrm{A}^{2}\right) \alpha+2 \mathrm{AB} \beta\right\} \cos 2 \beta t\right. \\
& \int V^{2} d t=\frac{\left.+\left\{\left(B^{2}-A^{2}\right) \beta-2 A B \alpha\right\} \sin 2 \beta t\right]}{4\left(\alpha^{2}+\beta^{2}\right)} \\
& -\frac{\left(\mathrm{A}^{2}+\mathrm{B}^{2}\right) e^{-2 a t}}{4 \alpha}
\end{aligned}
$$

If, now, $\beta$ is large in comparison with $\alpha$, the first term may be disregarded in comparison with the last, and in particular

$$
\int_{0}^{\infty} \nabla^{2} d t=\frac{A^{2}+B^{2}}{4 \alpha} . \cdots . . .
$$

(b) Of two superposed oscillations each gives in the integral terms of the form deduced above; but the terms arising from the cross products of terms with different periods and decrements require especial investigation. Such a typical term is

$$
\int \mathrm{MN} \epsilon^{(\mu+\nu) t} d t=\frac{M N e^{(\mu+\nu) t}}{\mu+\nu}
$$


where

$$
\begin{array}{ll}
\mathrm{M}=\frac{\mathrm{A}+\mathrm{B} i}{2} ; & \mathrm{N}=\frac{\mathrm{C}+\mathrm{D} i}{2} ; \\
\mu=-\alpha+\beta i ; & \nu=-\gamma+\delta i .
\end{array}
$$

The sum of all such integrated terms, reduced to the trigonometrical form, if $\mathrm{V}$ be of the form is

$$
\mathrm{V}=e^{-\mathrm{a} t}(\mathrm{~A} \cos \beta t+\mathrm{B} \sin \beta t)+e^{-\gamma t}(\mathrm{C} \cos \delta t+\mathrm{D} \sin \delta t),
$$

$$
\left.\begin{array}{c}
e^{-(\alpha+\gamma) t}\left\{\begin{array}{l}
-[(\mathrm{AC}-\mathrm{BD})(\alpha+\gamma)+(\mathrm{BC}+\mathrm{AD})(\beta+\delta)] \cos (\beta+\delta) t \\
+[-(\mathrm{AC}-\mathrm{BD})(\beta+\delta)-(\mathrm{BC}+\mathrm{AD})(\alpha+\gamma)] \sin (\beta+\delta) t \\
(\alpha+\gamma)+(\beta+\delta)
\end{array}\right. \\
+\frac{-[(\mathrm{AC}+\mathrm{BD})(\alpha+\gamma)+(\mathrm{BC}-\mathrm{AD})(\beta-\delta)] \cos (\beta-\delta) t}{+[(\mathrm{AC}+\mathrm{BD})(\beta-\delta)-(\mathrm{BC}-\mathrm{AD})(\alpha+\gamma)] \sin (\beta-\delta) t} \\
(\alpha+\gamma)^{2}+(\beta-\delta)^{2}
\end{array}\right\} ;,
$$

which, taken between the limits 0 and $\infty$, is

$$
\begin{aligned}
\frac{(\mathrm{AC}-\mathrm{BD})(\alpha+\gamma)}{(\alpha+\gamma)^{2}}+(\mathrm{BC}+\mathrm{AD})(\beta+\delta) \\
+\frac{(\mathrm{AC}+\mathrm{BD})(\alpha+\gamma)+(\mathrm{BC}-\mathrm{AD})(\beta-\delta)}{(\alpha+\gamma)^{2}+(\beta-\delta)^{2}}
\end{aligned}
$$

or, if $\alpha$ and $\gamma$ are so small that they can be neglected in comparison with $\beta$ and $\delta$,

$$
\frac{\mathrm{BC}+\mathrm{AD}}{\beta+\delta}+\frac{\mathrm{BC}-\mathrm{AD}}{\beta-\delta},
$$

which is ordinarily small in comparison with the principal terms, and can be neglected.

(c) $\mathrm{V}$ is the sum of harmonic and oscillatory terms. The preceding discussion of case $b$ is immediately applicable by putting $\gamma=0$. In general also the period of the oscillation is so much less than that of the harmonic terms that $\delta$ is negligible in comparison with $\beta$, and our last expression reduces to $\frac{2 \mathrm{BC}}{\beta}$, which is entirely negligible in comparison with the principal terms.

In the case of the potential in the secondary circuit of our apparatus

$$
\int_{0}^{\infty} \mathrm{V}_{2}^{2} d t=\frac{\mathrm{A}_{2}{ }^{2}+\mathrm{B}_{2}{ }^{2}}{4 a \overline{\mathrm{K}}_{2}^{2}}+\frac{\mathrm{C}_{2}{ }^{2}+\mathrm{D}_{2}{ }^{2}}{4 \gamma \mathrm{K}_{2}{ }^{2}}
$$

which becomes, neglecting $\mathrm{B}_{2}$ and $\mathrm{D}_{2}$, and noting that $\mathrm{A}_{2}{ }^{2}=\mathrm{C}_{2}{ }^{2}$,

$$
\frac{\mathrm{A}_{2}{ }^{2}}{4 \mathrm{~K}_{2}{ }^{2}}\left(\frac{1}{\alpha}+\frac{1}{\gamma}\right)=\frac{\mathrm{A}_{2}{ }^{2}(\alpha+\gamma)}{4 \alpha \gamma \mathrm{K}_{2}{ }^{2}} \text {. }
$$


Substituting the values of $A_{2}$ from equation (20), and of $\alpha$ and $\gamma$ from equations (10) and (11), or directly from equations (2) to (i), rationalizing, and performing the neces sary algebraic simplifications, we get

$$
\int_{0}^{\infty} \mathrm{V}_{2}^{2} d t=\frac{\mathrm{V}_{0}^{2} \mathrm{M}^{2} \mathrm{~K}_{1}^{2}\left(\mathrm{R}_{1} \mathrm{~L}_{2}+\mathrm{R}_{2} \mathrm{~L}_{1}\right)}{2\left[\bar{R}_{1} \mathrm{R}_{2}\left(\mathrm{~L}_{1} \mathrm{~K}_{1}-\mathrm{L}_{2} \mathrm{~K}_{2}\right)^{2}+\mathrm{M}^{2}\left(\mathrm{R}_{1} \mathrm{~K}_{1}+\mathrm{R}_{2} \mathrm{~K}_{2}\right)^{2}\right]} .
$$

The "effective" potential squared will be this quantity multiplied by $2 n$, where $n$ is the frequency of the alternating current charging the condenser ; or, calling this $\overline{\mathrm{V}_{2}{ }^{2}}$,

$$
\overrightarrow{V_{2}^{2}}=\frac{n V_{0}^{2} M^{2} K_{1}^{2}\left(R_{1} L_{2}+R_{2} L_{1}\right)}{\mathrm{R}_{1} R_{2}\left(\mathrm{~L}_{1} \mathrm{~K}_{1}-\mathrm{L}_{2} \mathrm{~K}_{2}\right)^{2}+\mathrm{M}^{2}\left(\mathrm{R}_{1} \mathrm{~K}_{1}+\mathrm{R}_{2} \mathrm{~K}_{2}\right)^{2}} .
$$

The general expression for the current in either circnit is

$$
\begin{aligned}
\mathrm{I} & =\frac{d \mathrm{Q}}{d t}=\begin{array}{c}
e^{-\alpha t}\{(-\alpha \mathrm{A}+\beta \mathrm{B}) \cos \beta t+(-\alpha \mathrm{B}-\beta \mathrm{A}) \sin \beta t\} \\
+e^{-\gamma t}\{(-\gamma \mathrm{C}+\delta \mathrm{D}) \cos \delta t+(-\gamma \mathrm{D}-\delta \mathrm{C}) \sin \delta t\}
\end{array} ; \\
\int_{0}^{\infty} \mathrm{I}^{2} d t & =\frac{(-\alpha \mathrm{A}+\beta \mathrm{B})^{2}+(\alpha \mathrm{B}+\beta \mathrm{A})^{2}}{4 a}+\frac{\left(-\gamma(\mathrm{C}+\delta \mathrm{D})^{2}+(\gamma \mathrm{D}+\delta \mathrm{C})^{2}\right.}{4 \gamma} \\
& =\frac{\left(\alpha^{2}+\beta^{2}\right)\left(\mathrm{A}^{2}+\mathrm{B}^{2}\right)}{4 a}+\frac{\left(\gamma^{2}+\delta^{2}\right)\left(\mathrm{C}^{2}+\mathrm{D}^{2}\right)}{4 \gamma},
\end{aligned}
$$

which becomes, neglecting $\alpha^{2}, \gamma^{2}, \mathrm{~B}^{2}$, and $\mathrm{D}^{2}$ as small,

$$
\int_{0}^{\infty} \mathrm{I}^{2} d t=\frac{\beta^{2} \mathrm{~A}^{2}}{4 \alpha}+\frac{\delta^{2} \mathrm{C}^{2}}{4 \gamma} .
$$

Applying this to circuit 2, where $\mathrm{A}_{2}{ }^{2}=\mathrm{C}_{2}{ }^{2}$, and substituting and reducing as before, we get

$$
\int_{0}^{\infty} \mathbf{1}_{2}^{2} d t=\frac{\mathrm{K}_{1} \mathrm{~K}_{2} \mathrm{~V}_{0}^{2} \mathrm{M}^{2}\left(\mathrm{R}_{1} \mathrm{~K}_{1}+\mathrm{R}_{2} \mathrm{~K}_{2}\right)}{2\left[\mathrm{R}_{1} \mathrm{R}_{2}\left(\mathrm{~L}_{1} \overline{\mathrm{K}}_{1}-\mathrm{L}_{2} \mathrm{~K}_{2}\right)^{2}+\mathrm{M}^{2}\left(\mathrm{R}_{1} \mathrm{~K}_{1}+\mathrm{R}_{2} \mathrm{~K}_{2}\right)^{2}\right]},
$$

and the "effective" current squared is

$$
\overline{1_{2}^{2}}=\frac{n \mathrm{~V}_{0}^{2} \mathrm{M}^{2} \mathrm{~K}_{1} \mathrm{~K}_{2}\left(\mathrm{R}_{1} \mathrm{~K}_{1}+\mathrm{R}_{2} \mathrm{~K}_{2}\right)}{\mathrm{R}_{1} \mathrm{R}_{2}\left(\mathrm{~L}_{1} \mathrm{~K}_{1}-\mathrm{L}_{2} \mathrm{~K}_{2}\right)^{2}+\mathrm{M}^{2}\left(\mathrm{R}_{1} \mathrm{~K}_{1}+\mathrm{R}_{2} \mathrm{~K}_{2}\right)^{2}} .
$$

In the case of the primary circuit we shall see that with our arrangement the coefficient $\mathrm{C}_{1}$ decidedly preponderates over the others. Then we have

$$
\begin{gathered}
\int_{0}^{2} \mathrm{I}_{1}^{2} d t=\frac{\delta^{2} \mathrm{C}_{1}^{2}}{4 \gamma} \\
=\frac{-\left(\mathrm{L}_{1} \mathrm{~K}_{1}-\mathrm{L}_{2} \mathrm{~K}_{2}\right)\left(\mathrm{R}_{1} \mathrm{~K}_{1}-\mathrm{R}_{2} \mathrm{~K}_{2}\right) \sqrt{\left.\left(\mathrm{L}_{1} \mathrm{~K}_{1}-\mathrm{L}_{2} \mathrm{~K}_{2}\right)^{2}+4 \mathrm{M}^{2} \mathrm{~K}_{1} \mathrm{~K}_{2}\right]}}{4 \mathrm{~K}_{1} \mathrm{~K}_{2}\left[\mathrm{R}_{1} \mathrm{R}_{2}\left(\mathrm{~L}_{1} \mathrm{~K}_{1}-\mathrm{L}_{2} \mathrm{~K}_{2}\right)^{2}+\mathrm{M}^{2}\left(\mathrm{R}_{1} \mathrm{~K}_{1}-\mathrm{R}_{2} \mathrm{~K}_{2}\right)^{2}\right]} ;
\end{gathered}
$$

and $\overline{I_{1}^{2}}$ is this expression multiplied as usual by $2 n$. 
An interesting approximation is obtained when $R_{2} K_{2}$ is small in comparison with $\mathrm{R}_{1} \mathrm{~K}_{1}$, and is disregarded. Our three formulæ just obtained then become

$$
\begin{aligned}
& \overline{\mathrm{V}_{2}^{2}}=\frac{n \mathrm{~V}_{0}^{2} \mathrm{M}^{2} \mathrm{~K}_{1}^{2}\left(\mathrm{~L}_{2}+\mathrm{L}_{1} \frac{\mathrm{R}_{2}}{\mathrm{R}_{1}}\right)}{\mathrm{R}_{2}\left(\mathrm{~L}_{1} \mathrm{~K}_{1}-\mathrm{L}_{2} \mathrm{~K}_{2}\right)^{2}+\mathrm{R}_{1} \mathrm{M}^{2} \mathrm{~K}_{1}^{2}} ; . . \\
& \overline{\mathrm{J}_{2}^{2}}=\frac{n \mathrm{~V}_{0}^{2} \mathrm{M}^{2} \mathrm{~K}_{1}^{2} \mathrm{~K}_{2}}{\mathrm{R}_{2}\left(\mathrm{~L}_{1} \mathrm{~K}_{1}-\mathrm{L}_{2} \mathrm{~K}_{2}\right)^{2}+\overline{\mathrm{R}}_{1} \mathrm{M}^{2} \mathrm{~K}_{1}^{2}} ; \quad \text {. } \\
& n \mathrm{C}_{1}^{2}\left[\left(\mathrm{~L}_{1} \mathrm{~K}_{1}-\mathrm{L}_{2} \mathrm{~K}_{2}\right)^{2}+4 \mathrm{M}^{2} \mathrm{~K}_{1} \mathrm{~K}_{2}\right. \\
& I_{1}^{2}=\frac{-\left(\mathrm{L}_{1} \mathrm{~K}_{1}-\mathrm{L}_{2} \mathrm{~K}_{2}\right) \sqrt{\left.\left(\mathrm{L}_{1} \mathrm{~K}_{1}-\mathrm{L}_{2} \mathrm{~K}_{2}\right)^{2}+4 \mathrm{M}^{2} \mathrm{~K}_{1} \mathrm{~K}_{2}\right]}}{2 \mathrm{~K}_{2}\left[\mathrm{R}_{2}\left(\mathrm{~L}_{1} \mathrm{~K}_{1}-\mathrm{I}_{2} \mathrm{~K}_{2}\right)^{2}+\mathrm{R}_{1} \mathrm{M}^{2} \mathrm{~K}_{1}{ }^{2}\right]} \text {. }
\end{aligned}
$$

It will be noticed that $R_{1}$ and $R_{2}$ are involved in the same way in all the denominators, and that the numerators differ only by a constant factor which does not involve the resistances, except the first, which bas a term in $\frac{R_{2}}{R_{1}}$. Solving these equations for $R_{2}\left(L_{1} K_{1}-L_{2} K_{2}\right)^{2}+R_{1} M^{2} K_{1}^{2}$, and dividing by $\mathrm{M}^{2} \mathrm{~K}_{1}{ }^{2}$,

$$
\begin{gathered}
\mathrm{R}_{1}+\mathrm{R}_{2} \frac{\left(\mathrm{L}_{1} \mathrm{~K}_{1}-\mathrm{L}_{2} \mathrm{~K}_{2}\right)^{2}}{\mathrm{M}^{2} \mathrm{~K}_{1}^{2}}=\frac{n \mathrm{~V}_{0}^{2}\left(\mathrm{~L}_{2}+\mathrm{L}_{1} \frac{\mathrm{R}_{2}}{\mathrm{R}_{1}}\right)}{\overline{\bar{V}_{2}{ }^{2}}} \\
=\frac{n \mathrm{~K}_{2} \mathrm{~V}_{0}^{2}}{\overline{\bar{V}_{2}{ }^{2}}} . \\
=\frac{n\left(\mathrm { C } _ { 1 } ^ { 2 } \left[\left(\mathrm{~L}_{1} \mathrm{~K}_{1}-\mathrm{L}_{2} \mathrm{~K}_{2}\right)^{2}+4 \mathrm{M}^{2} \mathrm{~K}_{1} \mathrm{~K}_{2}\right.\right.}{2 \mathrm{M}^{2} \mathrm{~K}_{1}{ }^{2} \mathrm{~K}_{2} \overline{\mathrm{I}_{1}{ }^{2}}}
\end{gathered}
$$

In the case where the secondary circuit is closed, the expression for the current is of the form

$$
\begin{aligned}
\mathrm{I}=\frac{d \mathrm{Q}}{d t}=e^{-\alpha t}[( & -\alpha \mathrm{A}+\beta \mathrm{B}) \cos \beta t \\
& +(-\beta \mathrm{A}-\alpha \mathrm{B}) \sin \beta t]-\gamma\left(e^{-\gamma t} .\right.
\end{aligned}
$$

The integral $\int_{0}^{\infty} 1^{2} d t$ then consists of two principal parts. The last is, by direct integration,

$$
\frac{\gamma^{2} \mathrm{C}^{2}}{2 \gamma}=\frac{\gamma \mathrm{C}^{2}}{2}
$$

The first part, by the preceding discussion, is

$$
\frac{(-\alpha \mathrm{A}+\beta \mathrm{B})+(-\beta \mathrm{A}-\alpha \mathrm{B})^{2}}{4 \alpha}=\frac{\left(\alpha^{2}+\beta^{2}\right)\left(\mathrm{A}^{2}+\mathrm{B}^{2}\right)}{4 \alpha} .
$$


Then, in the primary circuit,

$$
\int_{0}^{\infty} \mathrm{I}_{1}^{2} d t=\frac{\left(\alpha^{2}+\beta^{2}\right)\left(\mathrm{A}_{1}^{2}+\mathrm{B}_{1}^{2}\right)}{4 \alpha}+\frac{\gamma \mathrm{C}_{1}^{2}}{2} .
$$

By making the proper substitutions, and disregarding small quantities, this may be reduced to the form

$$
\int_{0}^{\infty} \mathrm{I}_{1}^{2} d t=\frac{\mathrm{V}_{0}{ }^{2} \mathrm{~L}_{2}{ }^{2} \mathrm{~K}}{2\left(\mathrm{~L}_{2}^{2} \mathrm{R}_{1}+\mathrm{M}^{2} \mathrm{R}_{2}\right)^{2}} . .
$$

In the secondary circuit

$$
\int_{0}^{\infty} \mathrm{I}_{2}^{2} d t=\frac{\left(\alpha^{2}+\beta^{2}\right)\left(\mathrm{A}_{2}^{2}+\mathrm{B}_{2}^{2}\right)}{4 \alpha}+\frac{\gamma \mathrm{C}_{2}^{2}}{2}
$$

which similarly ean be reduced to the form

$$
\int_{0}^{\infty} I_{2}^{2} d t=\frac{V_{0}^{2} M^{2} K}{2\left(L_{22}^{2} R_{1}+M^{2} R_{2}\right)} . \quad . \quad .
$$

\section{Description of Apparatus.}

In the experiments to be described, the immediate source of current was a large induction-coil, capable of giving at the secondary terminals on open circuit an effective difference of potential of twenty-one thousand $(21,000)$ volts when operated from the commercial alternating cireuit of fifty volts. This was exciled in various ways-by current from a storage battery, by the commercial circuit spoken of above, and by current from a small alternator kindly loaned by Prof. Pupin, of Columbia University.

The condensers in the primary cireuit of the oscillating system were sheets of micanite, $10 \times 12 \times 40$ inches, coated on both sides with tinfoil to within about an inch and a half of the edge. They were arranged symmetrically in two groups of two, and their capacity measured in electromagnetic units by the method suggested by Maxwell * and employed by J. J. Thomson $\dagger$ and Glazebrook $\Varangle$.

The condenser employed in the secondary circuit consisted of two circular brass disks, slightly convex, of about ten centimetres diameter, immersed in kerosene oil (petroleum). Its capacity was computed approximately, but no attempt was made to measure it.

The primary coil contained 34.5 turns of heavy wire, was $22 \mathrm{cms}$. long, and $8.3 \mathrm{cms}$. in mean diameter. The secondary

* Treatise, vol. ii. $\$ 776$.

† Phil. Trans. clxxiv. part 3, p. 707 (1883).

† Phil. Mag. (5) x viii. p. 98 (1884). 
had 84 turns in three layers, was about $30 \mathrm{cms}$. long, and $10.6 \mathrm{cms}$. in external diameter. The coefficients of induction were measured by the simple bridge method suggested by Maxwell *, using alternating current and telephone; and as a standard a coil of rectangular cross section, whose selfinduction was computed by the method of Stefan $\uparrow$.

Fig. 1.

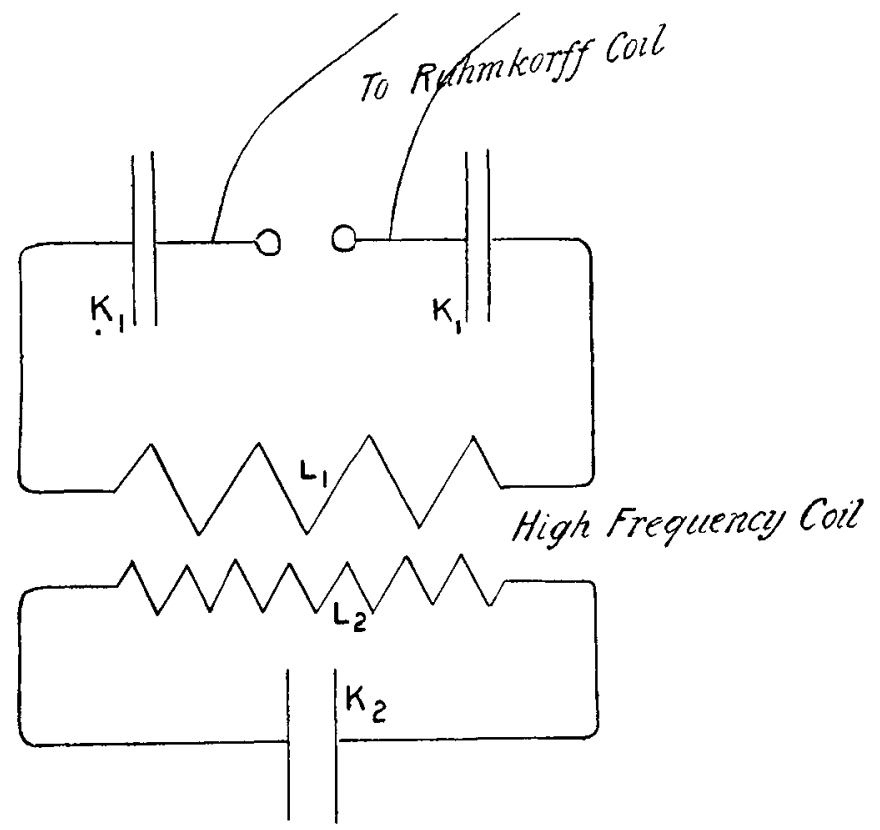

The primary spark passed between two balls of zinc, 2 centim. in diameter, and was blown out by an air-blast from a Sturtevant blower drivon by a sinall electric motor. The phenomena so obtained were more regular than when the spark passed in oil.

The electrical dimensions of different parts of the system, in c.G.s. absolute electromagnetic units, are as follows:-

$1,105,000=$ Self-induction of standard coil.

$\mathrm{L}_{1}=54,000=$ Self-induction of primary coil.

$\mathrm{L}_{2}=454,000=$ Self-induction of secondary coil.

$\mathrm{M}=77,000=$ Mutual-induction of the two coils.

$\mathrm{K}_{1}=1.6 \times 10^{-18}=$ Capacity of primary condenser.

$\mathrm{K}_{2}=2 \times 10^{-20}=$ Capacity of secondary condenser, when present.

* Treatise, vol. xi. $\S \S 756,757$.

$\dagger$ Wied. Ann. xxii. pp. 107-117 (1884).

Phil. Mag. S. 5. Vol. 46. No. 280. Sept. 1898. 
The resistances of the two coils to steady currents are small, of the order of $\cdot 05$ and $\cdot 3 \mathrm{ohm}$ respectively. $R_{1}$ and $R_{2}$ will, however, contain not only these, increased perhaps considerably on account of the peripheral distribution of the current, but also the resistances of whatever measuringinstruments are inserted, and of the spark-gaps, where such exist.

\section{Period.}

If in equation (19) we insert these values, we find

$$
A_{1}=.03 \mathrm{~V}_{0} \mathrm{~K}_{1} ; \quad \mathrm{C}_{1}=.97 \mathrm{~V}_{0} \mathrm{~K}_{1} .
$$

That is, the oscillation whose period is determined by the value of $\delta$ decidedly predominates in the primary circuit. This is due simply to the choice of dimensions of the system. The corresponding frequency hardly differs from the natural frequency of the primary system.

The experimental determinations of the period of oscillation were made by photographing a spark by means of a rotating mirror. The mirror itself was concave, silvered on the face, of about 36-centim. focal length, and mounted on the end of the shaft of an electric motor. The photographic plates were set at a distance of 81.5 centim. from the centre of the face of the mirror, and the speed of the motor was determined by comparison with a standard tuning-fork by a stroboscopic method.

The photographs of the most value were taken of the spark in the primary circuit. Some were taken also of that in the secondary circuit; but these seem by the theory to represent an oscillation superposed upon a current dying away logarithmically, and the photographs are correspondingly hazy. In each photograph there appear several distinct sparks, each showing fine striations, which indicate the oscillations (see fig. 2) . $^{*}$

In Table I. are given (a) the number of revolutions per second of the mirror, $(b)$ the number of oscillations distinctly visible in a given photograph, (c) the mean length of an oscillation, (d) the double frequency of oscillation computed from $a$ and $c$.

The dimensions of our apparatus would give, substitating in equation (9),

ard the frequency would be

$$
\delta=3,400,000 ;
$$

$$
\frac{\delta}{2 \pi}=5 \pm 2,000 \text {. }
$$

* In each photograph there appear sereral distinct sparks, each showing fine striations, which indicate the oscillations. These are unfortunately hardly visible in the reproductions. 
The mean observed double frequency, from the table, is $1,017,000$, which would give the observed frequency 510,000 nearly. This is as good a degree of agreement as could be expected, considering the degree of accuracy of our knowledge of the constants of the system.

Fig. 2.
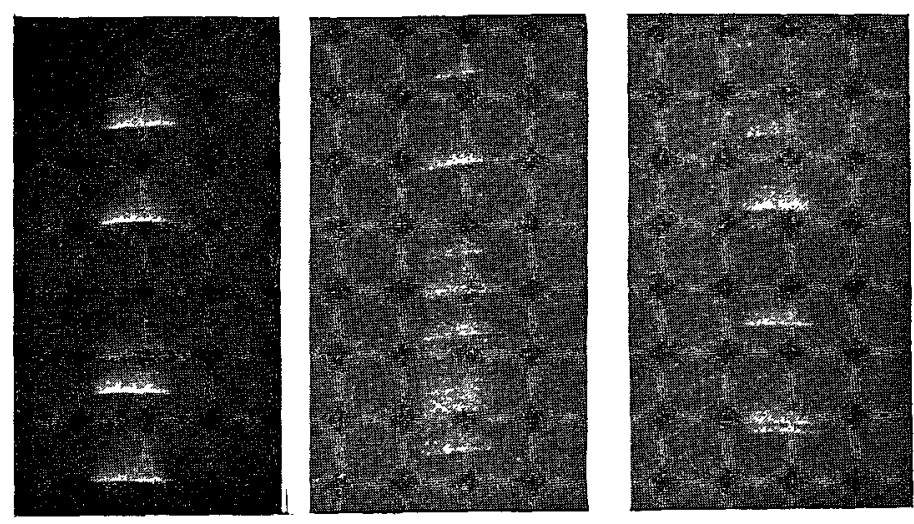

Tabee I.

\begin{tabular}{|c|c|c|c|}
\hline$a$. & $b$. & $c$. & $d$. \\
\hline 50 & 4 & 05 & $1.026 \times 10^{5}$ \\
50 & 6 & .05 & 1.026 \\
50 & 9 & .053 & .963 \\
50 & 4 & .05 & 1.026 \\
50 & 6 & .053 & .963 \\
50 & 7 & .051 & .998 \\
50 & 6 & .047 & 1.097 \\
50 & 10 & .05 & 1.026 \\
50 & 6 & 05 & 1.026 \\
64 & 4 & .06 & 1.093 \\
64 & 3 & .063 & 1.037 \\
64 & 5 & .07. & .939 \\
64 & 7 & .064 & 1.026 \\
64 & 5 & .068 & .967 \\
64 & 7 & .063 & 1.044 \\
\hline
\end{tabular}

\section{Maximum Potenticl.}

It appears from equation (20) that the greatest difference of potential which we can have in the secondary circuit is

$$
\frac{2 \mathrm{C}_{2}}{\mathrm{~K}_{2}}=\frac{2 \mathrm{~V}_{0} \mathrm{MK}_{1}}{\sqrt{\left(\mathrm{L}_{1} \mathrm{~K}_{1}-\mathrm{L}_{2} \overline{\mathrm{K}}_{2}\right)^{2}+4 \mathrm{M}^{2} \mathrm{~K}_{1} \overline{\mathrm{K}}_{2}}}=2 \cdot 7 \mathrm{~V}_{0} .
$$


The maximum potential was tested, roughly, by the measurement of spark-lengths, using for potentials of less than 30,000 volts determinations made by myself with the alternating current upon the absolute electrometer; higher potentials were taken from curves drawn from data given by Heydweiller *, potentials above 50,000 volts being obtained, when necessary, by extrapolation.

In the accompanying Table II., which gives a few out of a great number of determinations, column $a$ gives the length of the primary spark, $b$ is the corresponding potential $\mathrm{V}_{0}, c$ is the length of the secondary spark, $d$ the potential corresponding thereto, and $e$ the ratio $d / b$, which should have for its limit, as shown above, the value $2 \cdot 7$. The extreme values found range from 1.3 to 2.74 , with averages in different groups of from $1 \cdot 7$ to $2 \cdot 34$.

TABLe II.

\begin{tabular}{|c|c|c|c|c|}
\hline$a$. & $b$. & $c$. & $d$. & $e$. \\
\hline 8 & 24,500 & $3 \cdot 19$ & 53,100 & $2 \cdot 165$ \\
\hline " & ", & $2 \cdot 84$ & 51,200 & $2 \cdot 09$ \\
\hline ", & $"$ & 33 & 53,700 & $2 \cdot 19$ \\
\hline$"$ & " & 25 & 49,300 & $2 \cdot 01$ \\
\hline ", & ", & 289 & 51,500 & $2 \cdot 1$ \\
\hline$"$ & $"$ & $2 \cdot 11$ & 46,200 & 1.88 \\
\hline$"$ & ", & $\begin{array}{l}2 \cdot 25 \\
0.07\end{array}$ & 47,300 & 1.93 \\
\hline$"$ & $"$ & 207 & 45,900 & 187 \\
\hline$"$ & , & 2.51 & 49,200 & 201 \\
\hline$\ddot{6}$ & $19 \ddot{450}$ & $2 \cdot 4$ & 48,400 & 1.97 \\
\hline , & 10, & $\begin{array}{l}1.87 \\
2.65\end{array}$ & 44,200 & $\begin{array}{l}2 \cdot 27 \\
0.50\end{array}$ \\
\hline ", & " & $\begin{array}{l}200 \\
1.5\end{array}$ & $\begin{array}{l}n 0,400 \\
40,400\end{array}$ & 208 \\
\hline ," & ", & 1.28 & 37,200 & 1.91 \\
\hline$"$ & $"$ & $1 \cdot 06$ & 33,000 & 1.7 \\
\hline " & , & $1 \cdot 35$ & 38,400 & $1 \cdot 97$ \\
\hline$\pi$ & & 1.24 & 36,600 & $1 \cdot 88$ \\
\hline$\cdot 4$ & 13,650 & $1 \cdot 08$ & 30,400 & $2 \cdot 225$ \\
\hline " & $"$ & 75 & 23,500 & 1.72 \\
\hline " & $"$ & 68 & 21,650 & $2 \cdot 585$ \\
\hline$"$ & ", & 775 & 24,100 & $1 \cdot 76$ \\
\hline$"$ & ", & 78 & 24,200 & $1 \cdot 77$ \\
\hline " & ", & 725 & 22,800 & $1 \cdot 67$ \\
\hline$"$ & $"$ & 75 & 23,500 & 1.72 \\
\hline .0 & & 765 & 23,900 & $1 \cdot 75$ \\
\hline 2 & 7,300 & •555 & 18,300 & 2.505 \\
\hline$"$ & " & 27 & 9,500 & $1 \cdot 30$ \\
\hline$"$ & $"$ & .020 & $\begin{array}{l}11,300 \\
16000\end{array}$ & 1.55 \\
\hline$"$ & ", & .375 & 12,900 & 1.77 \\
\hline & & & & \\
\hline
\end{tabular}

The measurements of the effective difference of potential in the secondary circuit were made by means of a modified * Wied. Ann. xlviii. p. 213 (1893). 
quadrant electrometer used idiostatically. Only one of the quadrants was retained, and the needle was supported on a horizontal axis with jewelled benrings (fig. 3). These bearings.

Fig. 3.

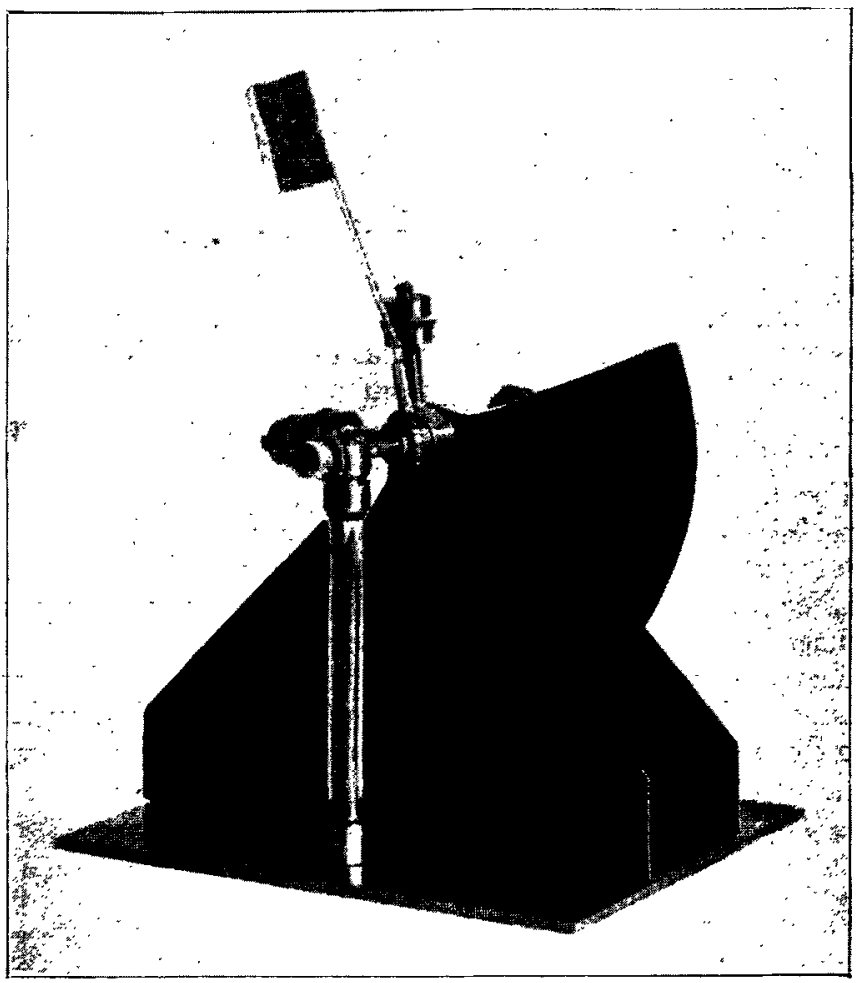

were carried on glass pillars, but on account of the high frequency the metallic parts had to be electrically connected to the needle. Neglect of this precaution resulted in the destruction of one of the jewels. The needle had suitable adjustments for level and sensitiveness and carried a plane mirror, enabling its deflexions to be read with mirror and scale. The whole was immersed in kcrosene oil, to prevent sparking. The oil served also as a damper to mechanical motions, and to increase the sensitiveness. The instrument gave a calibration-curve which was an almost perfect parabola, Its constant was frequently redetermined by the absolute attracted-disk electrometer belonging to the University*.

* See Edmondson, Physical Review, Feb. 1898. 
The effective currents were measured by a form of hot-wire ammeter or dynamometer due to Hertz *. The current traversed a fine german-silver wire which held a small steel wire in equilibrium against the torsion of a spring (fig. 4). The

Fig. 4.

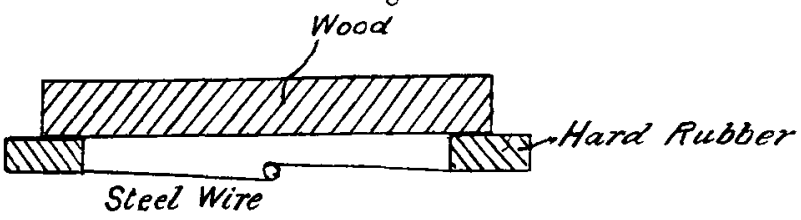

heat due to the current expanded the wire and allowed the steel wire to rotate under the influence of the spring. The deflexions were read with mirror and scale. These instruments were repeatedly calibrated, using a storage battery and known resistances, or current from a step-down transformer through a known non-inductive resistance, or by comparison with various Weston ammeters. The results were gratifyingly uniform. The sizes of wire used were numbers $30,36,40$, with carrying capacity varying from 2 to $: 5$ amperes. The instruments were very deadbeat, and particularly in the case of the smaller wires came to the final readings very promptly and returned to zero almost as promptly.

The sensitive quadrant electrometer just described was connected in parallel with the secondary capacity $\mathrm{K}_{2}$, and the two dynamometers were inserted in convenient positions in

Fig. 5.

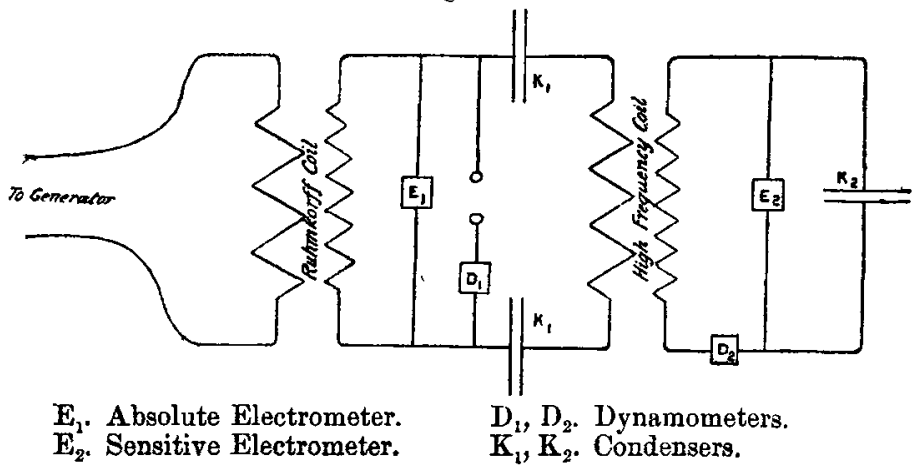

the primary and secondary circuits. After many trials of different positions, the dynamometer for the primary circuit was placed in the branch containing the spark-gap (fig. 5).

The terminals of the secondary circuit of the large inductioncoil were permanently connected to the absolute electrometer, as well as to the primary condenser of the oscillatory system.

- Zeitschr. fur Inst. iii. pp. 17-19 (1883); Ges. Werke, Bd. i. p. 227. 
In taking a series of observations the primary spark-gap is at first disconnected, and the current through the primary circuit of the Ruhmkorff coil is adjusted by inserting resistance or varying the excitation of the dynamo. Then the terminal difference of potential of the primary condenser is determined by the absolute electrometer and recorded.

The next step is to connect in the primary spark-gap, adjusting its length if necessary. Then starting the blower, and allowing the spark to pass, readings are made of the deflexions of the sensitive electrometer in the secondary circuit and of both dynamometers. These readings are repeated several times, allowing the instruments to return to zero after each reading; and then the primary spark-gap is again removed and the potential given by the Ruhmkorff again noted, for a check. The great variations of potential and frequency of the commercial circuit necessitated the use of an independent generator of current. Table III. contains part of the data thus taken. In column $a$ is recorded the primary spark-length in centimetres; under $V_{0}$ the potential corresponding thereto; under $b$ the maximum potential impressed upon the primary condenser when the spark-gap is removed, computed on the assumption of a true sine-current. The columns $\overline{I_{1}}, \overline{I_{2}}, \overline{V_{2}}$ give the observed effective currents in both circuits, and potential in the secondary circuit, respectively. Fig. 6.

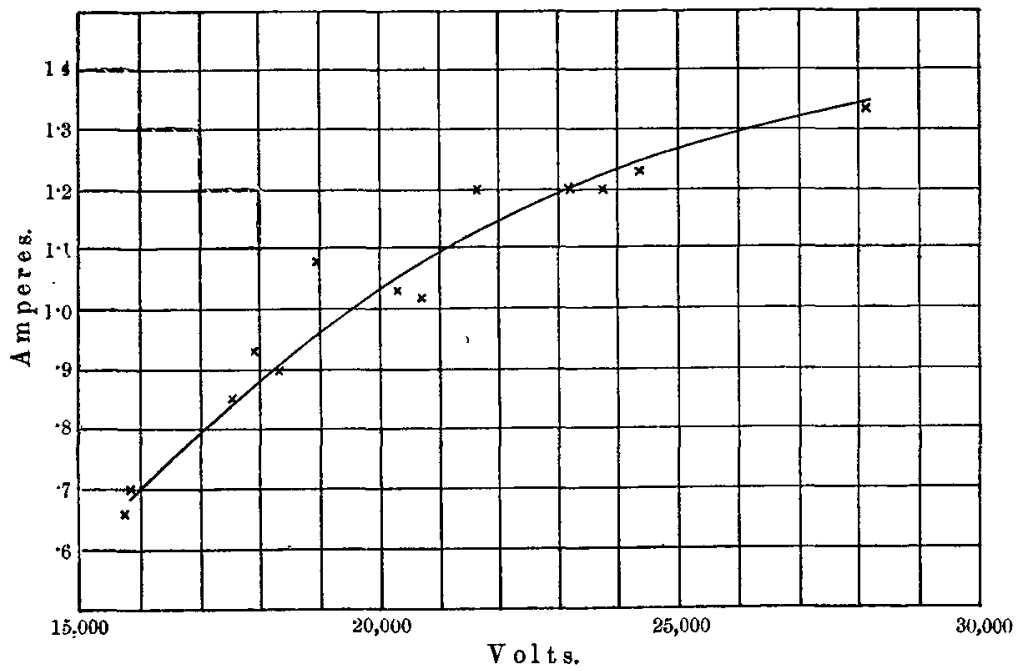

The maximum impressed difference of potential, $b$, has been used as the most available parameter for the intercomparison of data, and is taken as abscissa in the accompanying plot 
(fig. 6), which gives the observed effective primary current for a primary spark-length of $4 \mathrm{~mm}$. All the curves for $\overline{I_{1}}, \overline{I_{2}}$, and $\overline{V_{2}}$ aro of similar character, and show a decided rise with what may be called increasing excitation. The same was true, but in less degree, of the maximum sparklength in the secondary circuit, the data for which in Table. I., however, are not classified with reference to this point. The question immediately arises as to the reason for this behaviour. The most obvious suggestion is that, on account of the excess of current supplied to the condenser, the maximum potential effective at the primary spark-gap is greater than that indicated by its length. This suggestion is decidedly negatived, however, by the fact that the spark-length in the secondary circuit consistently falls short of the value possible on theoretical grounds. It would appear rather that the cause of the variation in our phenomena is the variable resistance of the primary spark, and that the helpful influence of increasing excitation is simply due to the increase of current poured through the spark-gap at instants of formation of the spark, which serves to decrease its resistance.

If we substitute in equation (28) the values of the constants of our system, we get, for $n=125$,

$$
\begin{aligned}
& \mathrm{R}_{1}+\cdot 387 \mathrm{R}_{2}=\left(56 \cdot 8+\frac{6 \cdot 75 \mathrm{R}_{2}}{\mathrm{R}_{1}^{\prime}}\right) \times 10^{6} \frac{\mathrm{V}_{0}^{2}}{\overline{\mathrm{V}_{2}^{2}}} \\
& =2.5 \times 10^{-18} \frac{V_{0}^{2}}{\overline{\overline{1}_{2}^{2}}} \\
& =190 \times 10^{-18} \frac{V_{0}^{2}}{\overline{\overline{1}_{1}^{2}}} ; \\
& \text { and for } n=136 \text {, } \\
& \begin{aligned}
\mathrm{R}_{1}+\cdot 387 \mathrm{R}_{2} & =\left(61.8+\frac{7 \cdot 35 \mathrm{R}_{2}}{\mathrm{R}_{1}}\right) \times 10^{6} \frac{\mathrm{V}_{0}^{2}}{\overline{\mathrm{V}_{2}^{-2}}} \\
& =2.72 \times 10^{-18} \frac{\mathrm{V}_{0}^{2}}{\overline{\bar{l}_{2}^{2}}} \\
& =206 \times 10^{-18} \frac{\mathrm{V}_{0}^{2}}{\overline{\overline{1}_{1}^{2}}} .
\end{aligned}
\end{aligned}
$$

These values are for the absolute system of units. To change them into ohms, volts, and amperes, we must write for the coefficients of $10-3,-9$, and -9 respectively. The values of $R_{1}+-387 R_{2}$, computed according to these equations (assuming in the first that $\frac{R_{1}}{R_{2}}$ is small), are given in Table III., in the columns headed by $R_{1} . \quad R_{2}$ is a purely metallic resistance, while $R_{1}$ contains the spark-gap; so that the resistance of this spark is in all probability the greater part of the resistance $R_{1}+\cdot 387 R_{2}$. 
High-Frequency Induction-Coil.

TABLE III.-Series 1. $n=125$.

\begin{tabular}{|c|c|c|c|c|}
\hline$a$ & $v_{0^{*}}$ & $b$ & $\overline{\mathrm{V}}_{2}$ & $\mathbf{R}_{\mathbf{L}}$ \\
\hline 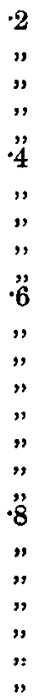 & $\begin{array}{c}7300 \\
" \\
\prime \\
13,650 \\
" \\
" \\
19,450 \\
" \\
" \\
" \\
" \\
" \\
24,500 \\
" \\
"\end{array}$ & $\begin{array}{r}9,900 \\
11,410 \\
14,000 \\
16,150 \\
18,050 \\
16,150 \\
19,800 \\
22,850 \\
22,850 \\
25,550 \\
22,120 \\
22,800 \\
24,900 \\
25,550 \\
28,600 \\
29,950 \\
27,400 \\
30,250 \\
26,160 \\
26,160 \\
26,750 \\
27,400 \\
27,700 \\
28,550 \\
29,900\end{array}$ & $\begin{array}{r}188 \\
260 \\
353 \\
482 \\
606 \\
458 \\
651 \\
956 \\
910 \\
1,013 \\
511 \\
723 \\
871 \\
825 \\
970 \\
1,210 \\
1,190 \\
1,230 \\
535 \\
671 \\
721 \\
777 \\
921 \\
975 \\
1,160\end{array}$ & $\begin{array}{l}85 \cdot 5 \\
45 \\
24 \cdot 4 \\
13 \\
8 \cdot 25 \\
51 \\
25 \\
11 \cdot 6 \\
12 \cdot 8 \\
8 \cdot 5 \\
8 \cdot 4 \\
41 \cdot 1 \\
28 \cdot 3 \\
31 \cdot 6 \\
22 \cdot 8 \\
14 \cdot 7 \\
15 \cdot 2 \\
14 \cdot 2 \\
119 \\
72 \\
65 \cdot 7 \\
57 \\
40 \cdot 2 \\
36 \\
25 \cdot 3\end{array}$ \\
\hline
\end{tabular}

Series 2. $n=136$.

\begin{tabular}{|c|c|c|c|c|}
\hline$a$. & $\nabla_{0}$ & $b$. & $\overline{\mathbf{V}}_{2}$ & $\mathbf{R}_{1}$ \\
\hline$\cdot 2$ & 7,300 & 8,670 & 186 & 95.4 \\
\hline$"$ & $"$ & 9,030 & 208 & $70 \cdot 1$ \\
\hline$"$ & $"$ & 11,850 & 232 & $61 \cdot 2$ \\
\hline$"$ & $"$ & 14,240 & 302 & $36 \cdot 1$ \\
\hline 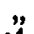 & $10 " 0$ & 18,070 & 350 & $27 \cdot 0$ \\
\hline$\cdot 4$ & 13,600 & 14,710 & 175 & 375 \\
\hline$"$ & $"$ & 16,650 & 290 & 136 \\
\hline$"$ & $"$ & 17,850 & 375 & $81 \cdot 8$ \\
\hline$"$ & " & 18,500 & 519 & $42 \cdot 7$ \\
\hline$"$ & $"$ & 21,050 & 740 & $21 \cdot 1$ \\
\hline " & $"$ & 2,300 & 811 & $17 \cdot 4$ \\
\hline " & $"$ & 24,170 & 900 & $14 \cdot 2$ \\
\hline${ }_{0}^{13}$ & $10 \not ̈ 50$ & 29,000 & 974 & $12 \cdot 2$ \\
\hline 6 & 18,450 & 19,770 & 204 & 560 \\
\hline$"$ & $"$ & 20,600 & 207 & 543 \\
\hline$"$ & " & 21,770 & 402 & $14 t$ \\
\hline$"$ & $"$ & 23,450 & 492 & 96 \\
\hline " & ", & 25,200 & 710 & 46 \\
\hline " & $"$ & 26,800 & 950 & $25 \cdot 9$ \\
\hline 0 & & 28,000 & 975 & $24 \cdot 6$ \\
\hline 8 & 24,500 & 25,600 & 269 & 512 \\
\hline$"$ & $"$ & 26,600 & 575 & 112 \\
\hline$"$ & " & 28,300 & 705 & 74 \\
\hline$"$ & $"$ & 29,500 & 720 & 712 \\
\hline ", & , & 30,520 & 915 & 44 \\
\hline
\end{tabular}


TABLE III. (con.).-Deries 3. $n=136$.

\begin{tabular}{|c|c|c|c|c|c|c|}
\hline a. & $\mathbf{V}_{0}$. & $b$. & $\overline{I_{1}}$. & $\mathbf{R}_{\mathbf{1}}$. & $\overrightarrow{I_{q}}$ & R. \\
\hline$\cdot 2$ & 7,300 & 9,900 & 73 & 205 & $\cdot 038$ & 100 \\
\hline$"$ & " & 10,400 & .635 & $27 \cdot 1$ & .037 & 106 \\
\hline$"$ & " & 14,100 & $1 \cdot 04$ & $10 \cdot 1$ & .057 & $44 \cdot 5$ \\
\hline$"$ & ", & 14,350 & 98 & $11 \cdot 4$ & .056 & $45 \cdot 8$ \\
\hline ", & $"$ & 18,050 & 1.26 & $6 \cdot 9$ & .07 & $29 \cdot 6$ \\
\hline & & 18,500 & $1 \cdot 19$ & $7 \cdot 7$ & .064 & $35 \cdot 4$ \\
\hline$\cdot 4$ & 13,650 & $15,6 \check{0} 0$ & 66 & $87 \cdot 5$ & .038 & 352 \\
\hline$"$ & $"$ & 15,840 & 70 & 77.8 & .045 & 250 \\
\hline$"$ & $"$ & 18,250 & 90 & $47 \cdot 3$ & 058 & 150 \\
\hline ", & ", & 18,900 & 1.08 & $32 \cdot 6$ & .065 & 120 \\
\hline ," & $"$ & 21,600 & $1 \cdot 20$ & $26 \cdot 6$ & .075 & 90 \\
\hline & " & 23,200 & 1.20 & 266 & 072 & 98 \\
\hline 6 & 19,450 & 20,200 & .56 & 246 & 03 & 1,145 \\
\hline$"$ & $"$ & 21,400 & .92 & 92 & .053 & 365 \\
\hline ", & , & 22,300 & 97 & 82 & .058 & 307 \\
\hline$"$ & $"$ & 26.500 & $1 \cdot 30$ & 46.3 & 076 & 178 \\
\hline 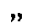 & , & 28,000 & $1+33$ & $44 \cdot 1$ & .075 & 182 \\
\hline & & 29,100 & 1.33 & $44 \cdot 1$ & .079 & 164 \\
\hline .8 & 24,500 & 25,850 & 1.03 & 116 & .056 & 521 \\
\hline$"$ & $"$ & 26,060 & 81 & 188 & .045 & 805 \\
\hline 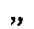 & ", & 28,000 & $1 \cdot 24$ & 80 & .078 & 268 \\
\hline 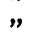 & ", & 29,100 & 1.23 & 81 & 07 & 332 \\
\hline$"$ & $"$ & 30,900 & 1.41 & 62 & 081 & 249 \\
\hline ", & $"$ & 32,500 & 1.47 & 57 & .09 & 202 \\
\hline
\end{tabular}

The numerical values obtained from these different sources are by no means identical, but the results deduced from the values of $\overline{\nabla_{2}}$ and $\overline{I_{1}}$ will be seen, on inspection, to agree fairly well; and all the results are concordant to this extent, that the values of the spark-resistance, as thus given, are all of the same order; and that this resistance is a variable, but not linear function of the current in the spark. Fig. 7 gives $R_{1}$ for the same spark-gap as fig. 6, 4 millim., using the same abscissa.

Whether this resistance falls off indefinitely or approaches some finite limit cannot be told from the limited amount of data here presented.

\section{Closed Secondary Circuit.}

Substituting in equation (21) the values of the capacity and inductances of our system, we get

$$
\beta=3.905 \times 10^{6} \text {, }
$$

which gives us the frequency

$$
\frac{\beta}{2 \pi}=622,000 \text {. }
$$


Fig. 7.

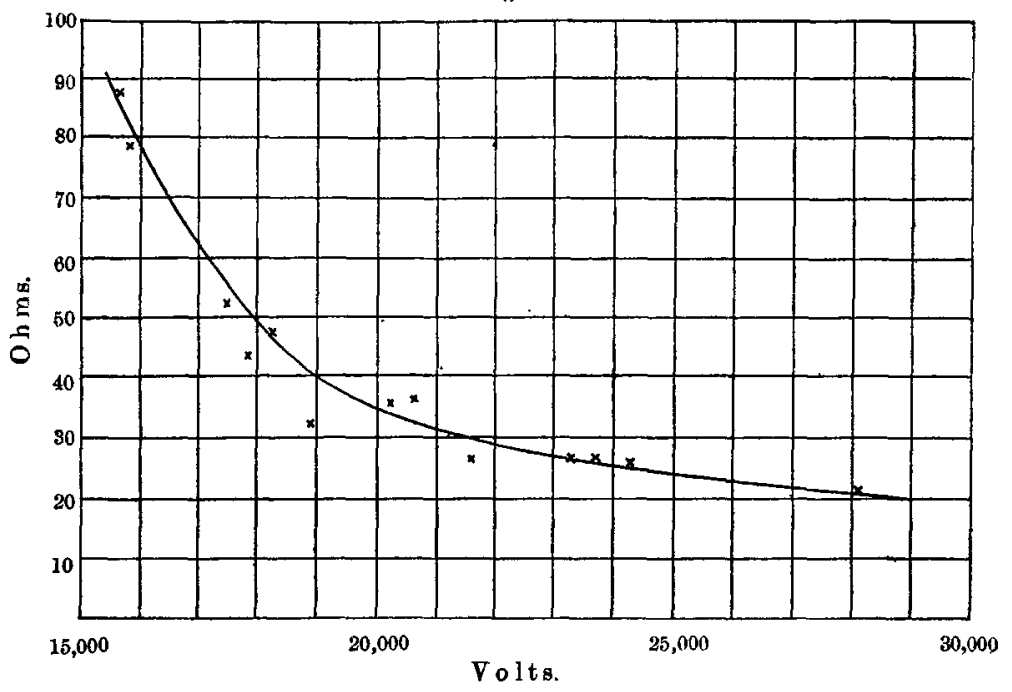

No direct measurements were made verifying this frequency. The fow spark-photographs made show mainly the hazy light due to the current expressed by the exponential term.

Substituting the values of capacity and inductances in equations (30) and (31), and reducing from the absolute to the practical system, we get

$$
\begin{aligned}
& \int_{0}^{\infty} \mathrm{I}_{1}^{2} d t=\mathrm{V}_{0}^{2} \frac{8 \times 10^{-10}}{\mathrm{R}_{1}+\cdot 1694 \mathrm{R}_{2}}, \\
& \int_{0}^{\infty} \mathrm{I}_{2}^{2} d t=\nabla_{0}^{2} \frac{1 \cdot 355 \times 10^{-10}}{\mathrm{R}_{1}+\cdot 1694 \mathrm{R}_{2}} .
\end{aligned}
$$

Solving for $R_{1}+\cdot 1694 R_{2}$, we get for $n=136$

$$
\begin{aligned}
\mathrm{R}_{1}+\cdot 1694 \mathrm{R}_{2} & =1.089 \times 10^{-7} \frac{\mathrm{V}_{0}{ }^{2}}{\overline{\bar{I}_{1}^{2}}} \\
& =1.845 \times 10^{-8} \frac{\mathrm{V}_{0}{ }^{2}}{\overline{\bar{I}_{2}^{2}}} .
\end{aligned}
$$

Table IV. gives in columns $a, \mathrm{~V}, b$, as before, the primary spark-length, the potential corresponding thereto, and the maximum impressed potential. In column $c$ are given the lengths of spark-gaps introduced into the secondary circuit, the spark taking place between brass balls 2 centim. in diameter. Columns $\bar{I}_{1}$ and $\overline{I_{2}}$ give the observed effective 
currents in the two circuits, while columns $d$ and $e$ give $R_{1}+\cdot 1694 R_{2}$, computed from $\bar{I}_{1}$ and $\overline{I_{2}}$ respectively by the equations just given.

TaBLe IV.

\begin{tabular}{|c|c|c|c|c|c|c|c|}
\hline$a$ & $\nabla_{0}$. & $b$. & $c$. & $\overrightarrow{I_{1}}$. & $d$. & $\overline{\mathrm{I}}_{2}$ & $e$. \\
\hline$\cdot 2$ & 7,300 & 8,200 & 0 & ·136 & 315 & .067 & 130 \\
\hline$"$ & ", & $"$ & .2 & $\cdot 124$ & 379 & $\cdot 18$ & 305 \\
\hline$"$ & $"$ & & $\cdot 3$ & $\cdot 11$ & 482 & $\cdot 188$ & 27.9 \\
\hline$"$ & ", & 10,000 & 0 & $\cdot 83$ & $8 \cdot 5$ & $\cdot 15$ & 438 \\
\hline$"$ & " & " & $\cdot \mathbf{1}$ & 78 & $9 \cdot 6$ & .2 & $24 \cdot 7$ \\
\hline$"$ & " & " & $\cdot 2$ & 73 & 10.95 & 31 & 1025 \\
\hline$"$ & , & " & 3 & 69 & $12 \cdot 25$ & 38 & 6.84 \\
\hline$"$ & ", & 11,430 & 0 & 96 & 6.33 & $\cdot 168$ & 35 \\
\hline$"$ & , & " & $\cdot 1$ & $\cdot 88$ & $7 \cdot 53$ & 2225 & $19 \cdot 5$ \\
\hline$"$ & ", & $"$ & $\cdot 2$ & 85 & 8.09 & $\cdot 295$ & $11 \cdot 33$ \\
\hline$"$ & ", & $y$ & $\cdot 3$ & $\cdot 80$ & $9 \cdot 12$ & $\cdot 415$ & 5.73 \\
\hline$"$ & ", & 12,800 & 0 & 1.06 & $5 \cdot 2$ & $\cdot 163$ & $37 \cdot 1$ \\
\hline$"$ & , & $"$ & $\cdot 1$ & 1.02 & $5 \cdot 6$ & 285 & $11 \cdot 33$ \\
\hline$"$ & , & , & 2 & .97 & 6.2 & $\cdot 355$ & 7.82 \\
\hline ", & " & & $\cdot 3$ & .95 & 647 & $\cdot 438$ & 513 \\
\hline$"$ & $"$ & 17,300 & 0 & $1 \cdot 25$ & 37 & $\cdot 215$ & $21 \cdot 3$ \\
\hline$"$ & " & $"$ & $\cdot 1$ & $1 \cdot 17$ & $4 \cdot 26$ & $\cdot 367$ & $7 \cdot 33$ \\
\hline$"$ & " & $"$ & $\cdot 2$ & $1 \cdot 14$ & $4 \cdot 48$ & $\cdot 41$ & $5 \cdot 88$ \\
\hline$\ddot{.0}$ & $13 " 350$ & "̈ & 3 & $1 \cdot 11$ & $4 \cdot 73$ & $\cdot 49$ & $4 \cdot 11$ \\
\hline$• 4$ & 13,650 & 14,900 & 0 & 7 & $4] \cdot 5$ & $\cdot 128$ & 210 \\
\hline$"$ & " & ", & $\cdot 1$ & .66 & $46 \cdot 7$ & $\cdot 237$ & $61 \cdot 3$ \\
\hline$"$ & $"$ & " & $\cdot 2$ & 61 & $54 \cdot 7$ & · 405 & 2] \\
\hline ", & " & & 3 & 54 & 698 & $\cdot 5$ & $13 \cdot 8$ \\
\hline$"$ & $"$ & 18,100 & 0 & $1 \cdot 15$ & $15 \cdot 33$ & $\cdot 16$ & 134.5 \\
\hline$"$ & ", & ", & 1 & $1 \cdot 12$ & $16 \cdot 2$ & $\cdot 244$ & 58 \\
\hline " & $" 1$ & $"$ & 2 & 1.08 & $18 \cdot 1$ & 311 & $35 \cdot 6$ \\
\hline$"$ & $"$ & " & 3 & 1.00 & $20-3$ & $• 481$ & 14.9 \\
\hline
\end{tabular}

It will be seen by reference to the table that the values of the resistances here found are of the same order as those found in the case of open secondary circuit.

It has been mentioned that the resistances $R_{1}$ and $R_{2}$ consist both of spark-gap and of metallic resistance.

Gray and Mathews* show that the virtual resistance of a straight metallic wire to very rapidly oscillating currents is

$$
\mathbf{R}^{\prime}=\sqrt{\frac{\mu n l \mathrm{R}}{2}} .
$$

Taking $\mu$ as unity, this can be reduced to the form

$$
\mathrm{R}^{\prime}=\mathrm{R} r \sqrt{\overline{\pi n}},
$$

* 'Treatise on Bessel's Functions,' p. 160. 
where $k$ is the conductivity. For $n=500,000$ and $k=\cdot 0006$, this gives the rather startling result

$$
\mathbf{R}^{\prime}=36,000 r \mathbf{R},
$$

which for wire of 1 millim. diameter would be

$$
\mathbf{R}_{1}^{\prime}=1,800 \mathbf{R} \text {. }
$$

This deduction assumes, however, that the wire is at an infinite distance from other currents, while in our case the distance between wires is comparable to their diameters. The results of our experimental work would also entirely contradict any assumption of such excessive increase in metallic resistance.

A brief comment upon the degree of accuracy attained and attainable in such work may be of interest. The behaviour of the dynamometers left nothing to be desired. They acted with much greater uniformity than the phenomena to be observed, so that any irregularity observed in their readings must be attributed to actual variations in the currents. As much can hardly be said of the electrometer. To give convenient readable deflexions with the mean potentials observed, it required to be adjusted with such sensitiveness that the directive force was not large enough to prevent frictional disturbance of the position of equilibrium. Further, the inertia of the moving system was such as to prevent prompt reading of deflexions, and in case of intermittent action the readings obtained were a time-average, which was necessarily small. The observations were of great value, however, because they were of a wholly different type of phenomenon, and furnished so good a check upon both the theoretical reasonings and the accuracy of the other work. In general the accuracy of the results obtained seems to have been conditioned almost entirely upon the uniformity of the phenomena of a blown-out spark in air.

In the foregoing work an attempt has been made to verify experimentally the agreement of the actual behaviour of an oscillating system with two degrees of freedom with the approximate theory. As specific conclusions resulting from this comparison we see that:-

1. The main period of oscillation of the primary circuit is very nearly that deduced from the dimensions of the system. The same may be said also of the maximum potential attained in the secondary circuit.

2. The effective currents and potentials, which are functions of the damping factors, and these in turn factors of the resistances, would indicate that the resistances of the sparks are of the order of from 10 to $100 \mathrm{ohms}$, depending upon the amount 
of current flowing through the spark. This conclusion is in gratifying agreement with the work of Trowbridge and Richards*, who have similarly used the damping effect upon an oscillatory current to measure the resistance, but have done this by direct substitution.

3. It appears from Table IV. that when the secondary circuit is closed by a spark, the primary current decreases with the length of this spark; but the secondary current decidedly increases. This behaviour is not explained by the approximate theory here deduced, but was most unmistakable both in early preliminary work and in the later more careful determinations here recorded. It still remains to be shown whether this is due to the conditions of the experiment, or is to be explained by a more -accurate application of theoretical reasoning.

In conclusion, it only remains for me to express my thanks to Professor A. G. Webster for his unfailing sympathy and helpfulness, which has rendered this work possible, and to Clark University which placed at my disposal the facilities for the work.

XXXI. Compound Line-Spectrum of Hydrogen.

By R. S. Hutton, B.Sc.†

\section{Introduction.}

THE general conclusion arrived at by spectroseopists with regard to the compound line-spectrum of hydrogen is that it really belongs to the element, and not to a hydrocarbon as was at one time supposed. Nevertheless the question cannot be said to be absolutely proved, especially in view of Cornu's experiments, which seemed to indicate that if the vacuum-tubes have been previously washed out with oxygen, the compound line-spectrum disappears, or at any rate becomes much weakened. It seemed to me to be of utility to repeat ('ornu's $\ddagger$ experiments in a different form, and also to prepare the hydrogen by methods different from those in common use.

2. Fractionation of the Hydrogen occluded by Palladium.

It first occurred to me that good results might be expected by carefully tractionating off the hydrogen absorbed by palladium \$; and although my attention was shortly after

* Phil Mag. (5) xliii. pp. 349-367 (1897).

+ Communicated by Arthur Schuster.

† A. Cornu, Journ. de Phys. ii. 5. pp. 100-103 \& 341-354 (1886).

\$ I was able to make use of this method by the great liberality of Messrs. Matthey in lending me 50 grams of palladium-foil, gratitude for wbich I wish to express here. 